\title{
Hypothermia and Stroke: Pros and Cons
}

\section{Firoozeh Alavian*}

Department of Basic Sciences, Farhangian University, Tehran, Iran

\section{A BSTRACT}

Introduction: Stroke is one of the main causes of mortality worldwide. Stroke survivors suffer from pain and a variety of physical disabilities as well as mood disorders, such as depression. More than $25 \%$ of stroke survivors permanently disabled and lose daily independence activities; thus, effective treatment is essential. For a long time, researchers have tried to find ways to reduce the brain damage following stroke. Trying to find Pharmaceutical ways in spite of the huge economic investment has failed. In addition to pharmacological treatments, rehabilitation of stroke is important. It is likely that molecular changes are crucial for spontaneous recovery. The purpose of this systematic review was to evaluate the effectiveness of hypothermia for reducing mortality and morbidity after stroke. This is a quantitative research to achieve the objectives using of the previous study analysis. Conclusion: Empirical work and clinical observation have shown the relationship between temperature and brain damage in stroke; in which stroke with fever is associated with a significant increase in mortality. Prevention of temperatures rising in the early stages of stroke has been advised. Although stroke rehabilitation is beneficial, significant achievements occurs within the first hours and days after the stroke. Understanding of the protective role of hypothermia may improve the efforts to reduce the brain injuries following stroke.

\section{Key words:}

1. Stroke

2. Hypothermia

3. Therapeutics

*Corresponding Author: Firoozeh Alavian

E-mail: F.Alavian@cfu.ac.ir 


\section{هاييوترمى و سكتهُ مغزى: مزايا و معايب}

\section{فيروزه علويان"}

حروه علوم پايه، دانشعاه فرهنَيان، تهران، ايران

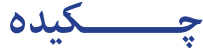

مقدمه: سكتعٔ مغزى يكى از علل اصلى مرگ و مير در سرتاسر جهان است. بازماندگًان سكتهٔ مغزى، از درد

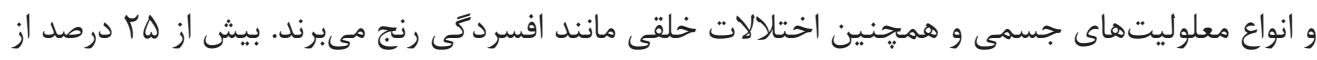

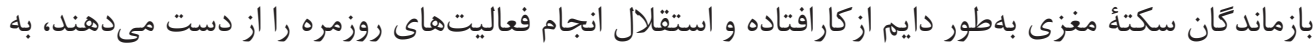

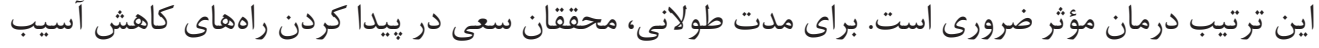

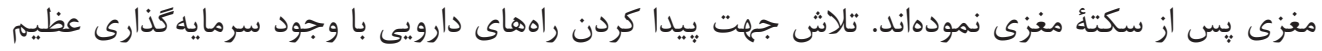

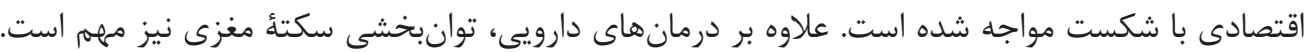

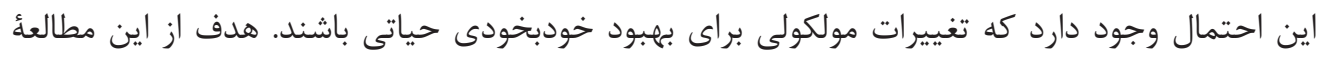

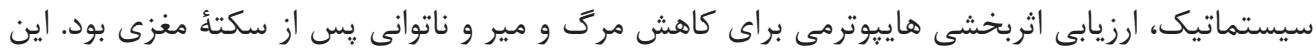

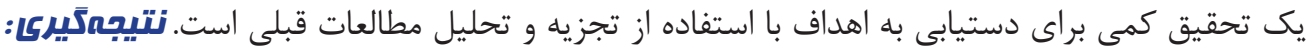

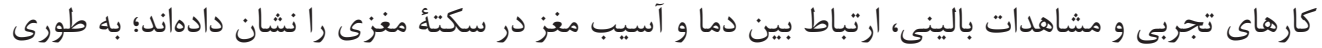

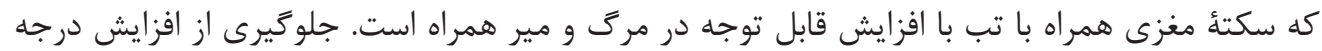

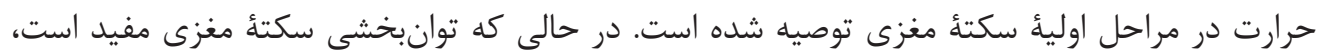

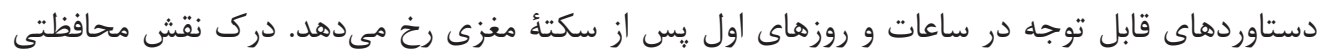

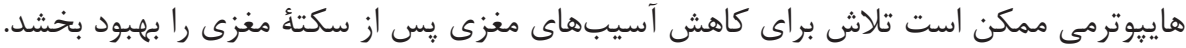

كليد وازمها:

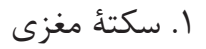

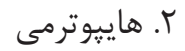

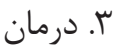

" نويسنده مسئول: فيروزه علويان

آدرس الكترونيكى: F.Alavian@cfu.ac.ir 


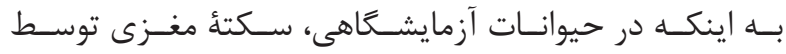
مقدمه

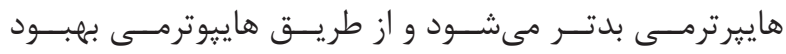

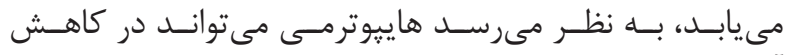

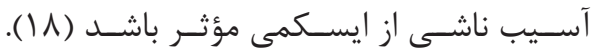

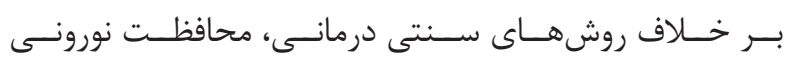

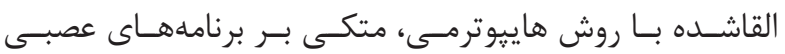

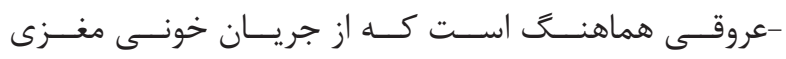

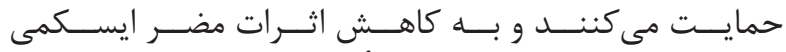

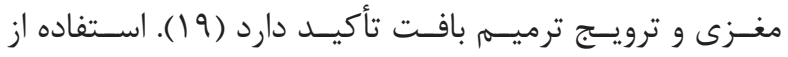

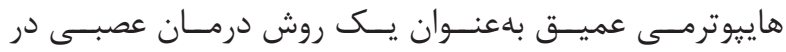

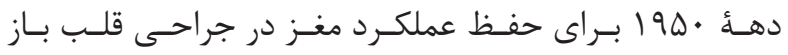

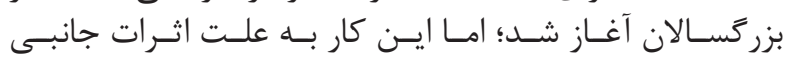

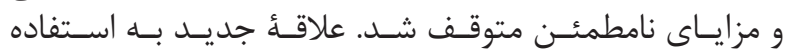

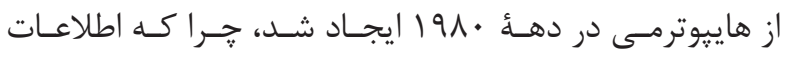

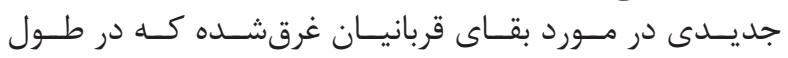

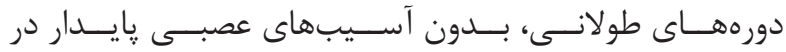

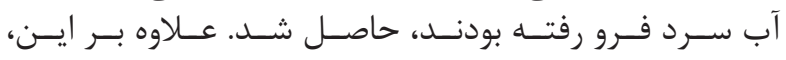

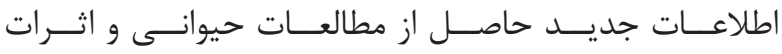

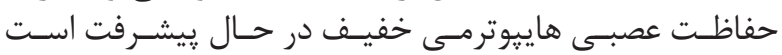

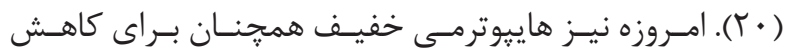

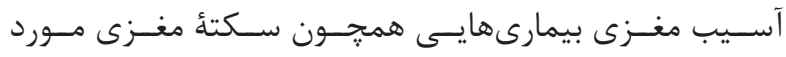

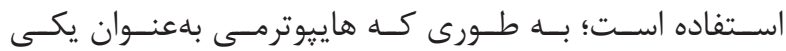

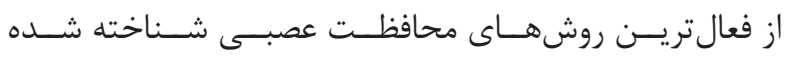

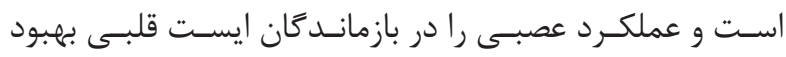

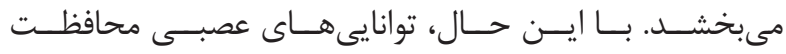

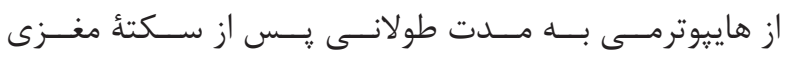

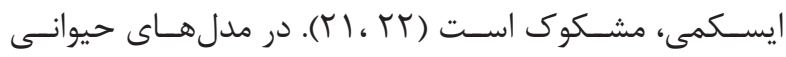

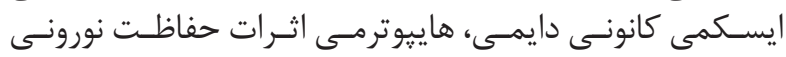

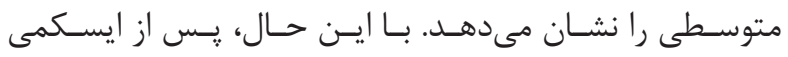

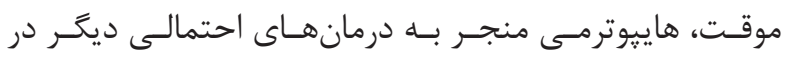

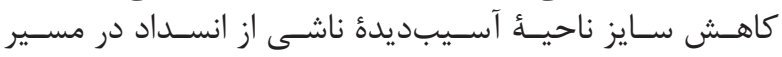

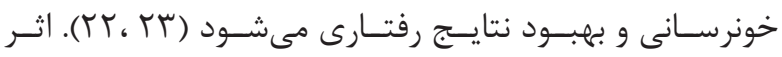

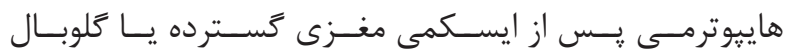

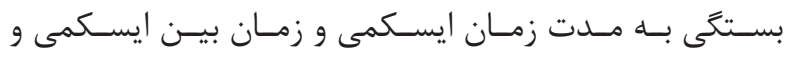

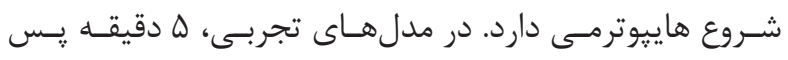

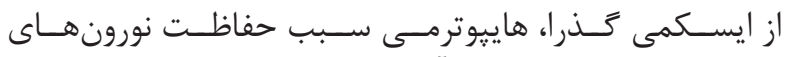

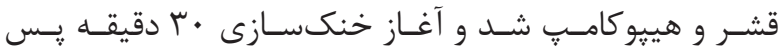

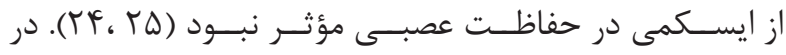

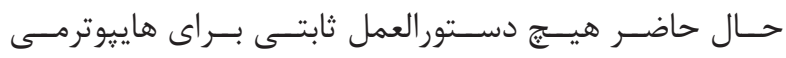

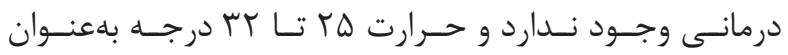

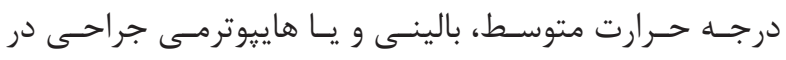

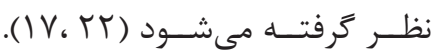

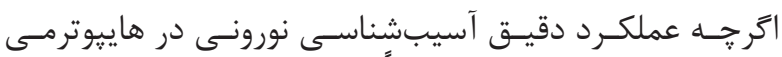

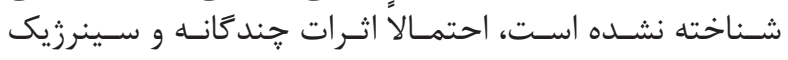

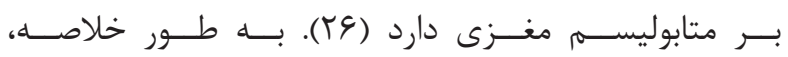

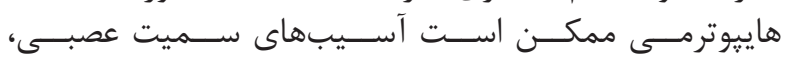

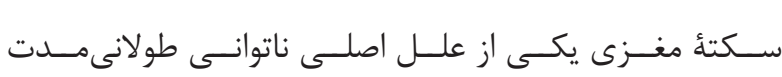

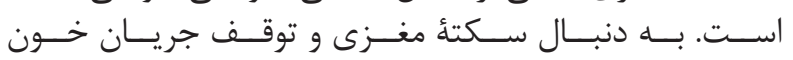

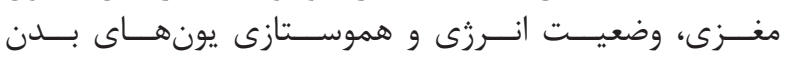

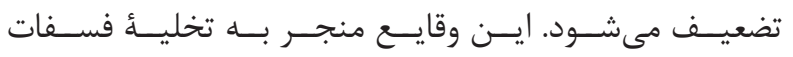

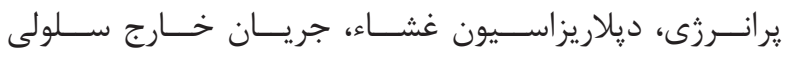

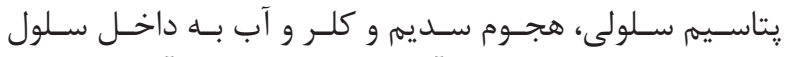

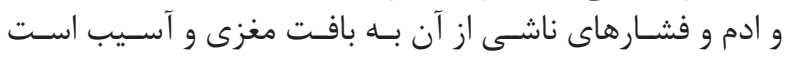

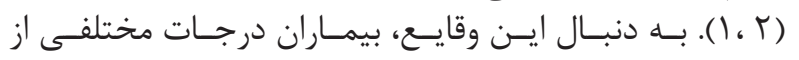

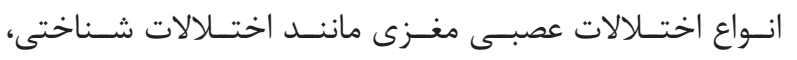

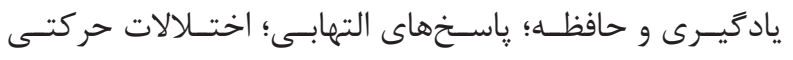

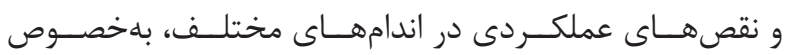

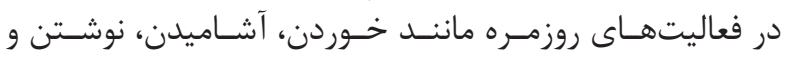

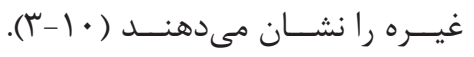

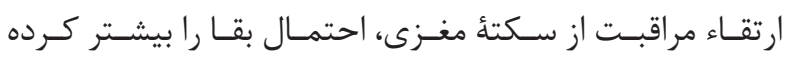

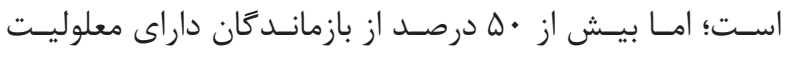

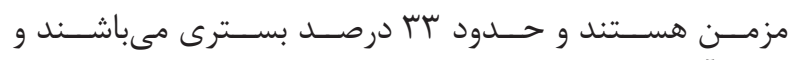

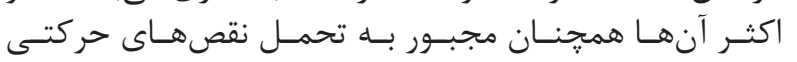

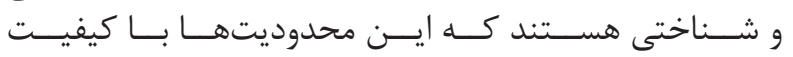

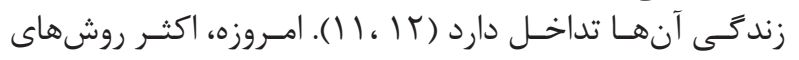

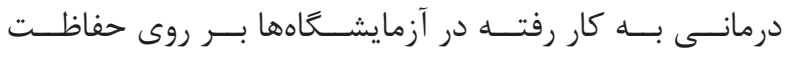

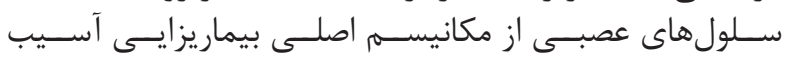

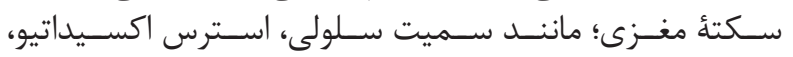

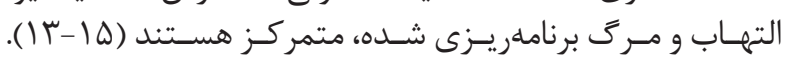

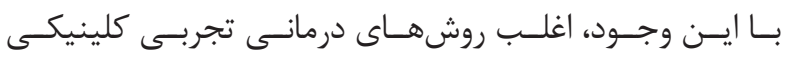

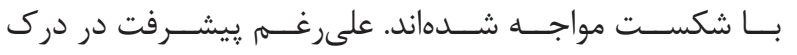

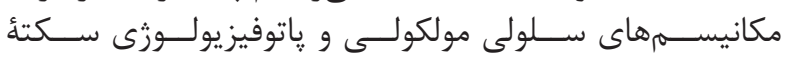

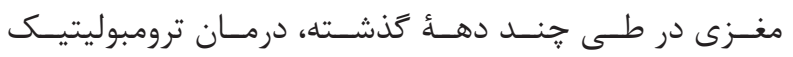

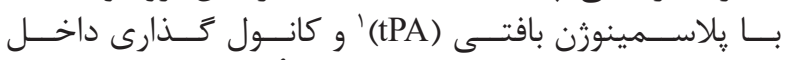

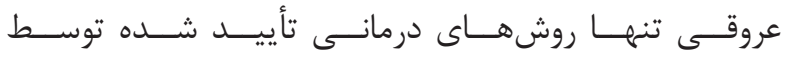

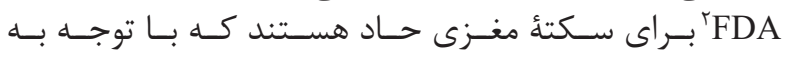

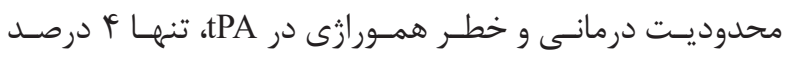

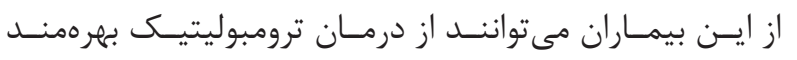

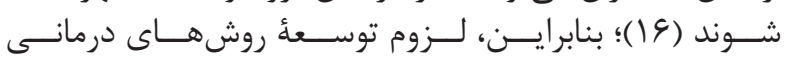

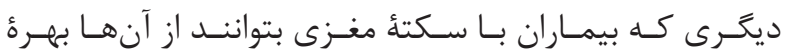

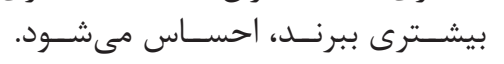

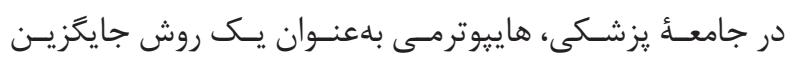

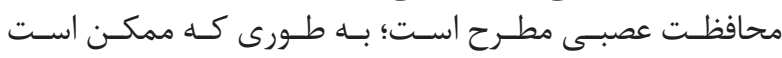

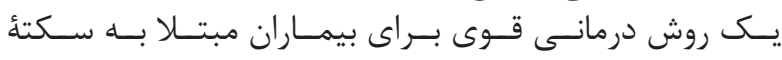

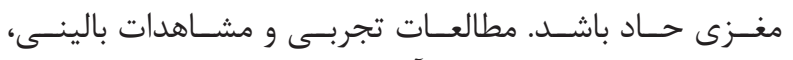

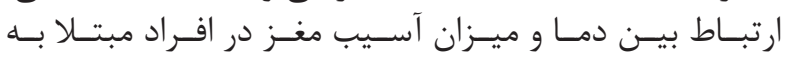

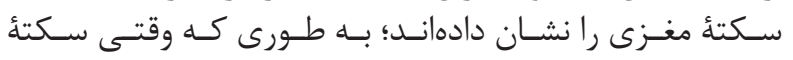

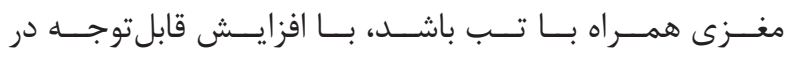

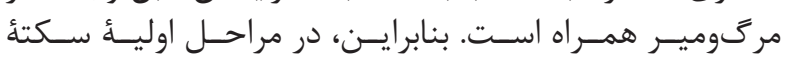

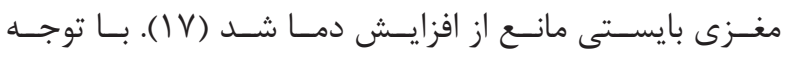

${ }^{1}$ Tissue plasminogen activator

${ }^{2}$ Food and drug administration 


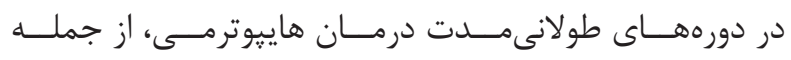

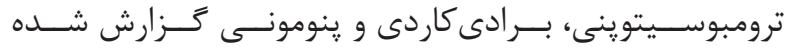

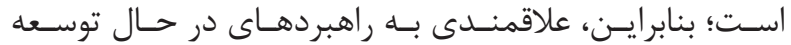

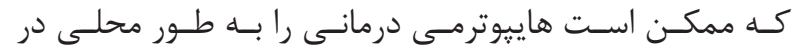

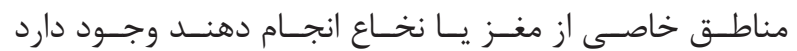

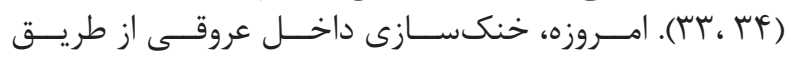

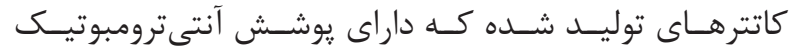

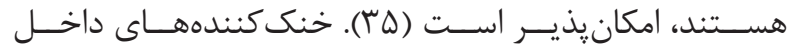

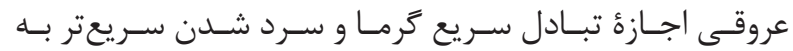

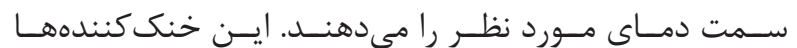

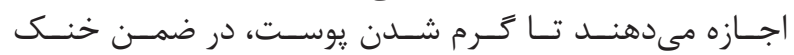

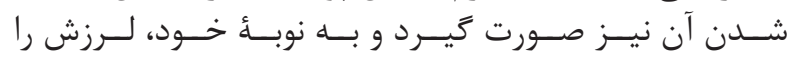

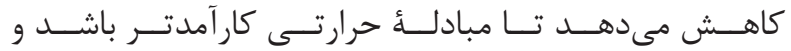

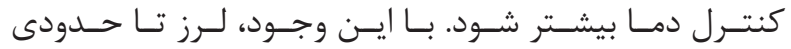

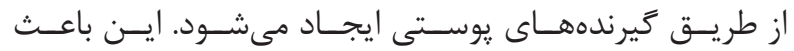

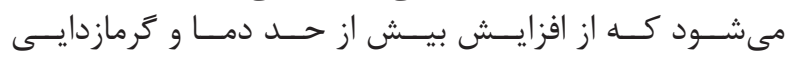

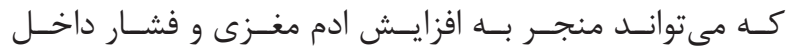

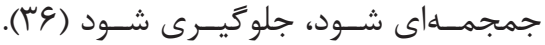

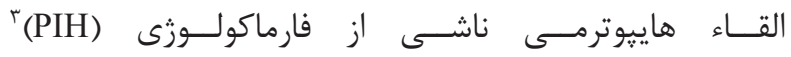

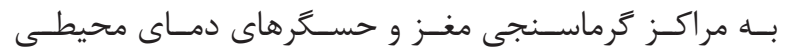

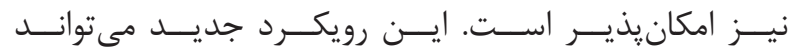

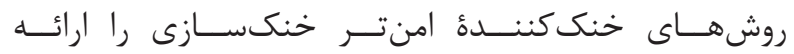

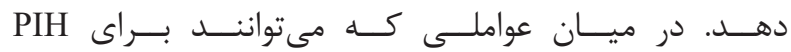

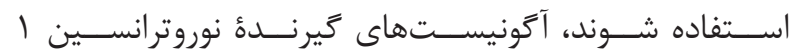
(NTR1)

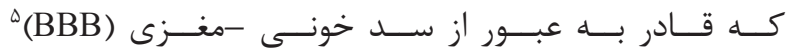

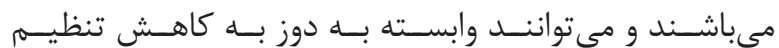

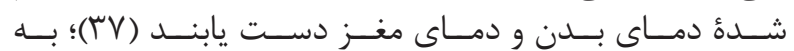

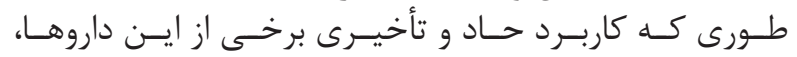

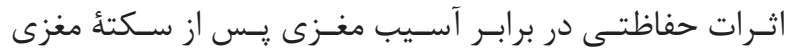

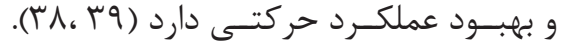

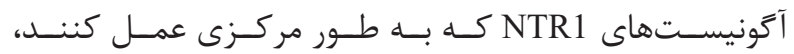

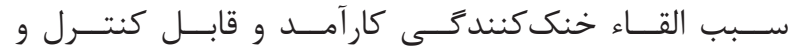

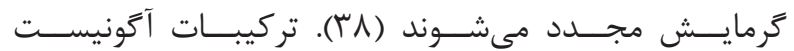

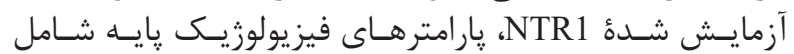

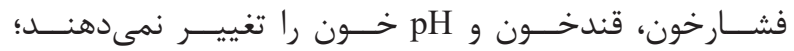

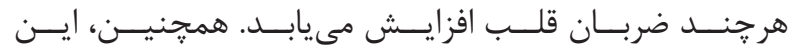

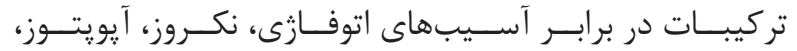

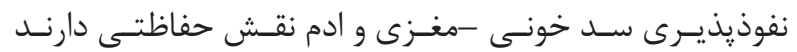

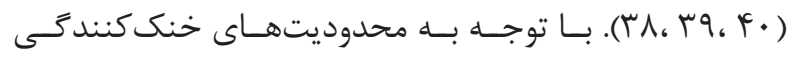

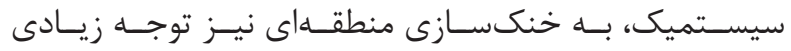

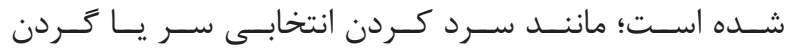

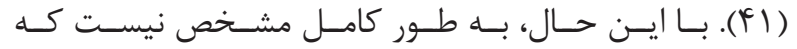

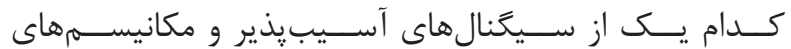

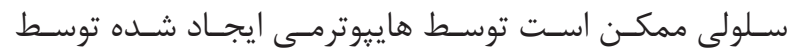

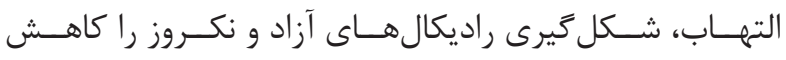

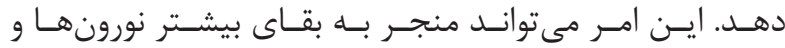

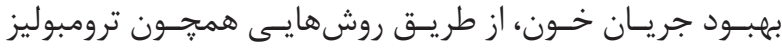

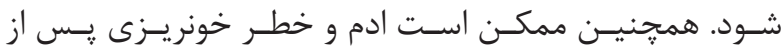

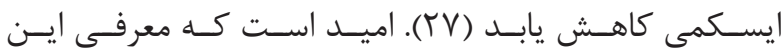

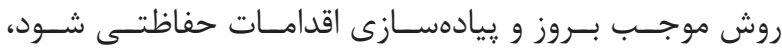

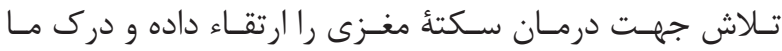

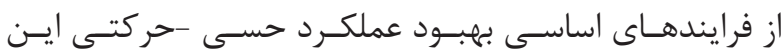

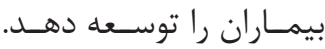

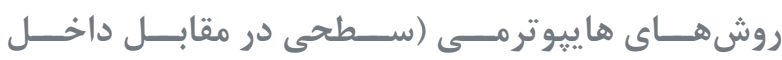

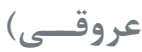

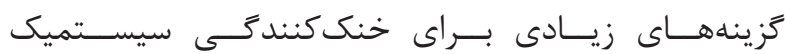

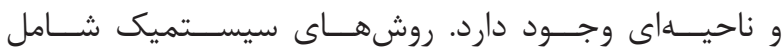

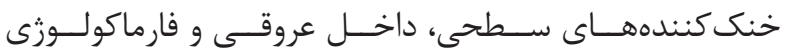

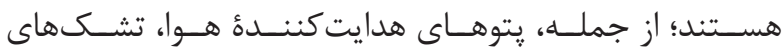

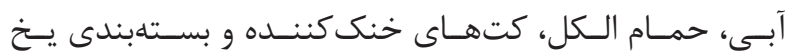

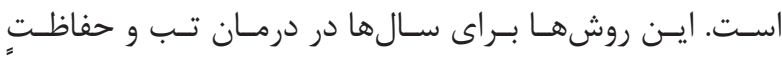

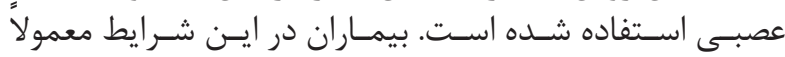

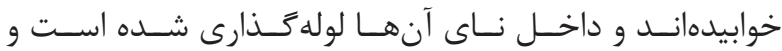

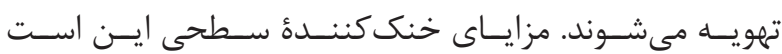

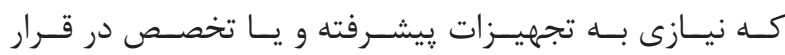

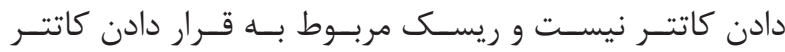

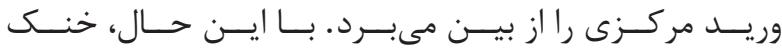

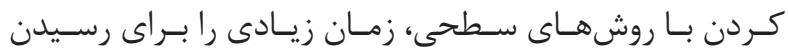

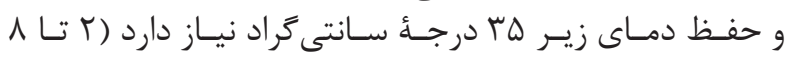

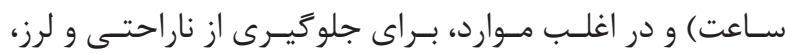

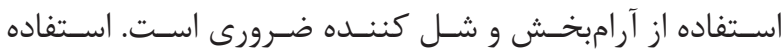

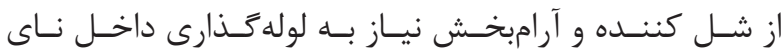

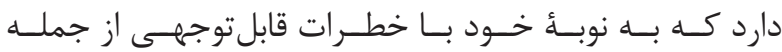

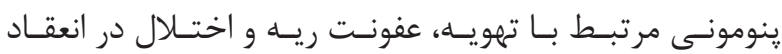

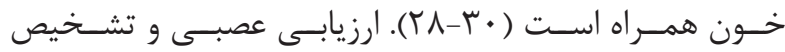

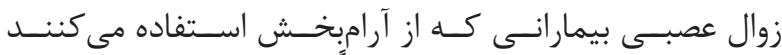

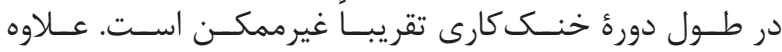

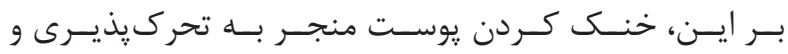

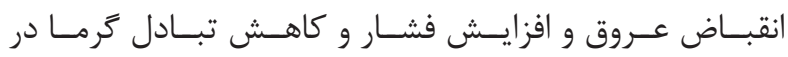

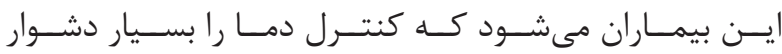

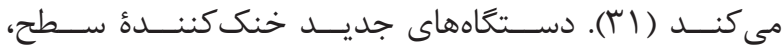

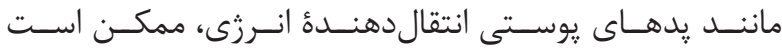

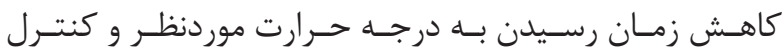

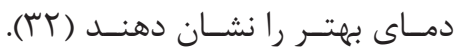

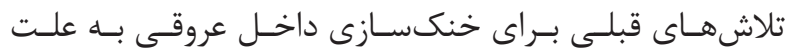

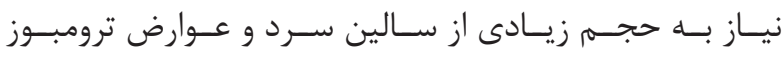

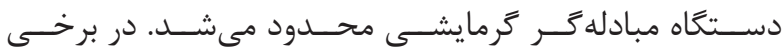

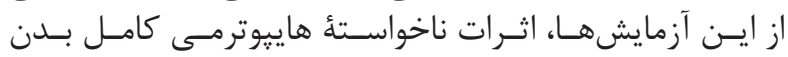

${ }^{3}$ Pharmacological induced hypothermia

${ }^{4}$ Neurotensin receptor 1

${ }^{5}$ Blood brain barrier 


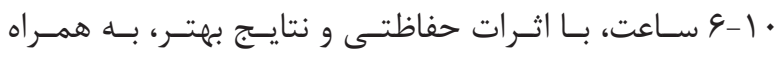

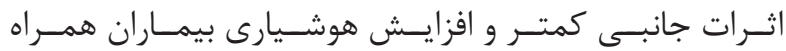
اسـت (rq).

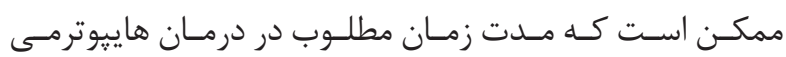

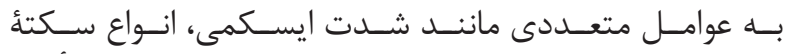

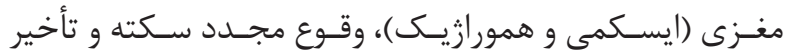

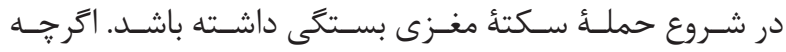

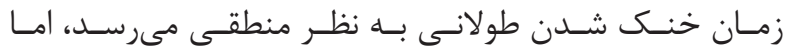

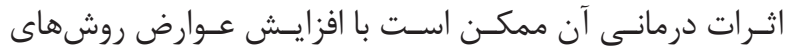

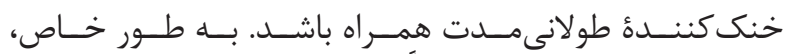

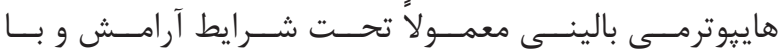

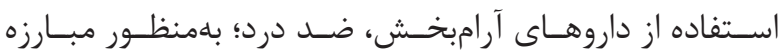

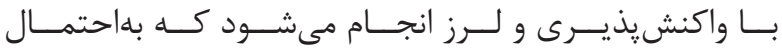

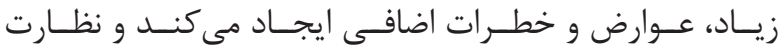

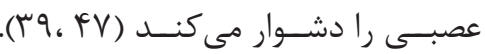
سازوكارها و نتايج فيزيولوزيكى هايبوترمى

\section{وقايع مولكولى اوليه}

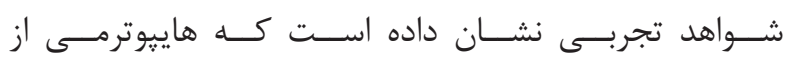

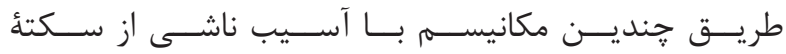

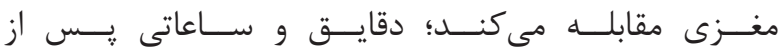

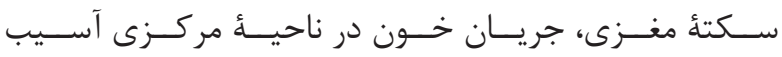

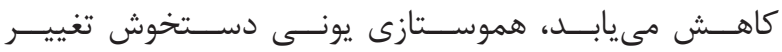

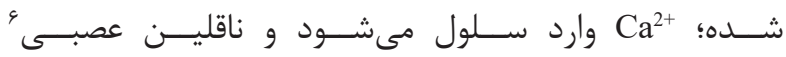

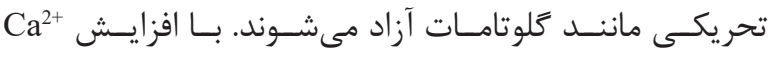

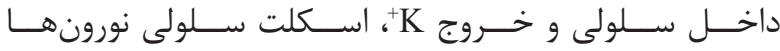

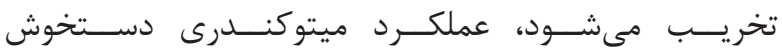

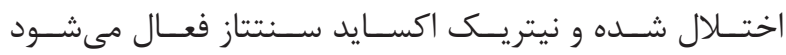

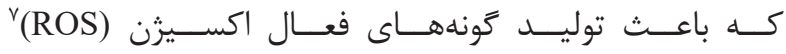

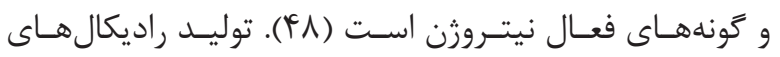

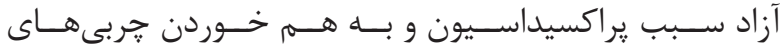

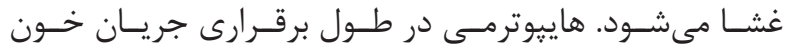

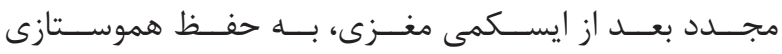

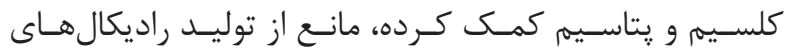

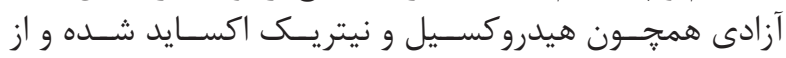

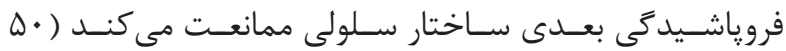

(l). $4 q$ ،

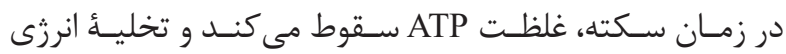

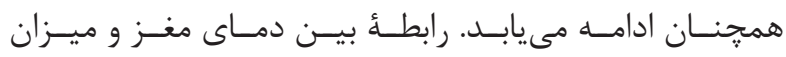

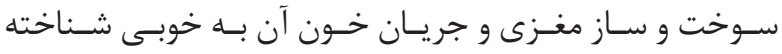

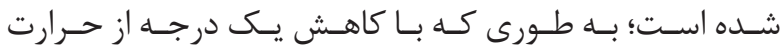

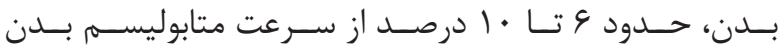

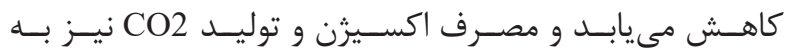

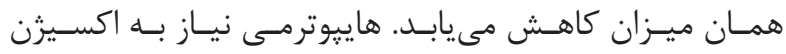

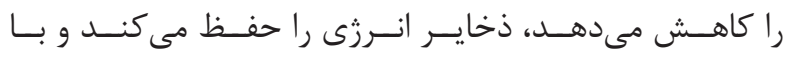

هــر دو روشهــاى دارويسى و فيزيكـى تنظيـهم شــوند.

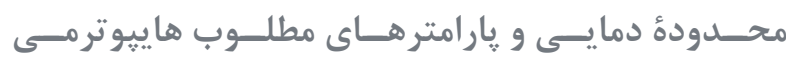
د

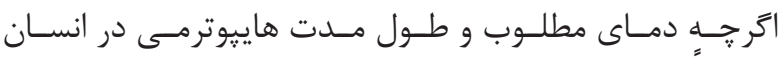

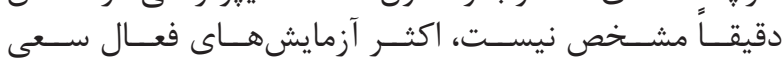

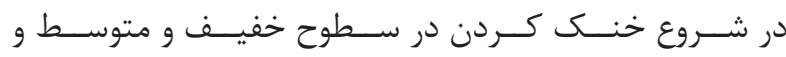

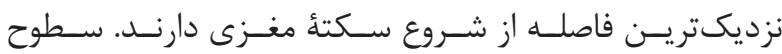

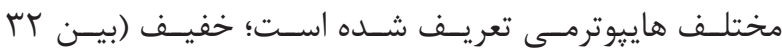

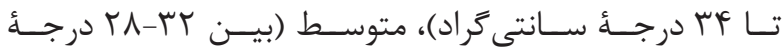

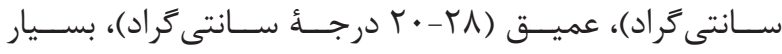

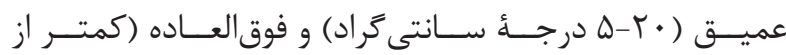

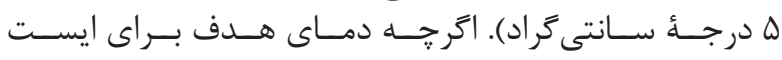

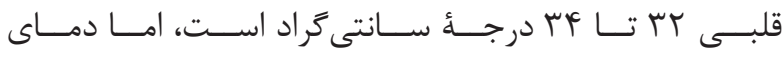

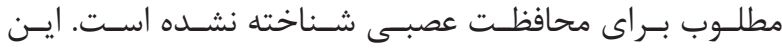

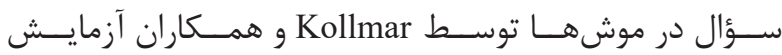

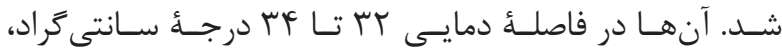

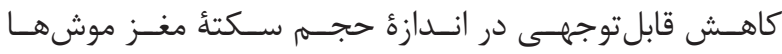

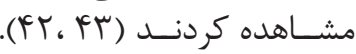

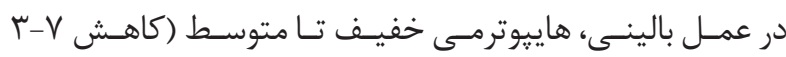

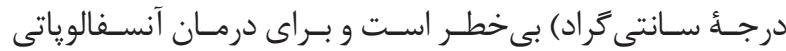

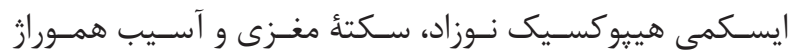

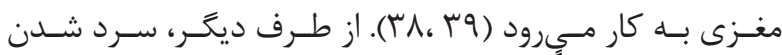

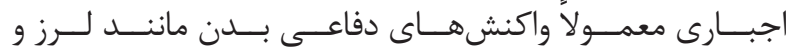

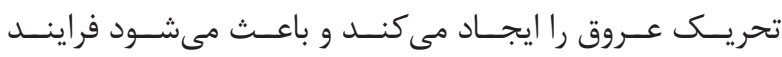

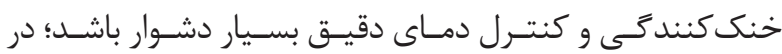

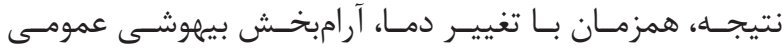

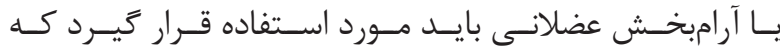

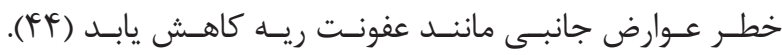

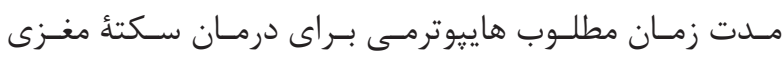

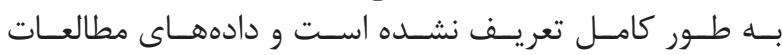

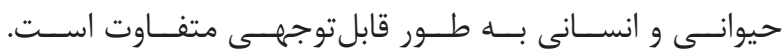

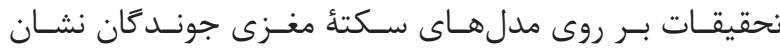

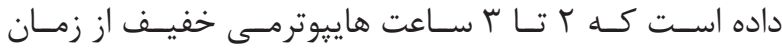

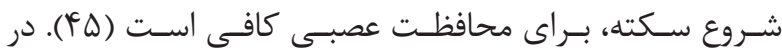

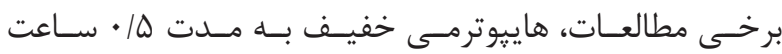

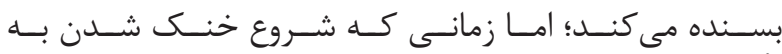

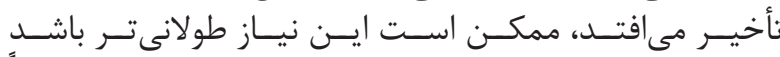

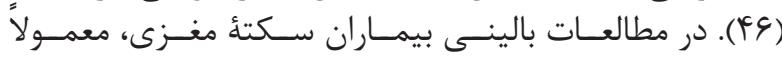

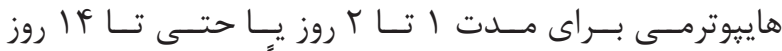

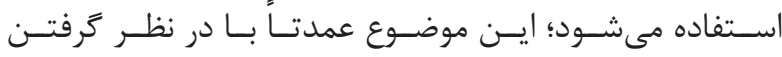

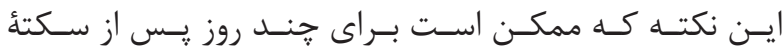

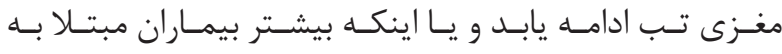

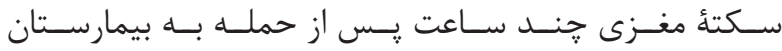

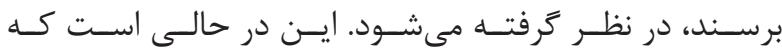

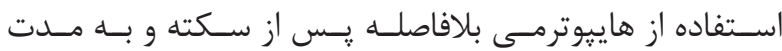

${ }^{6}$ Neurotransmitter

${ }^{7}$ Reactive oxygen species 


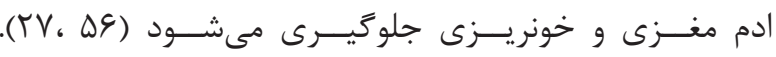

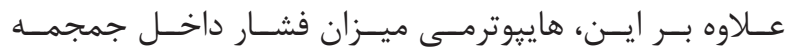

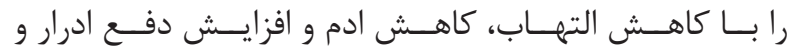

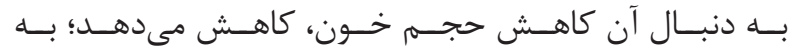

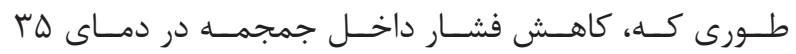

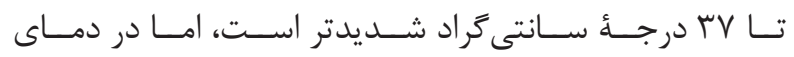

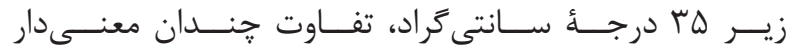

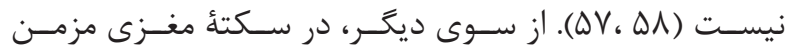

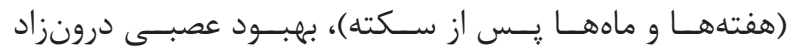

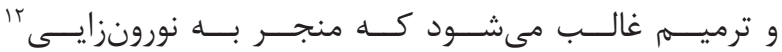

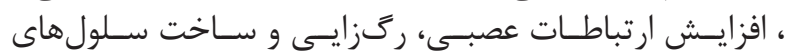

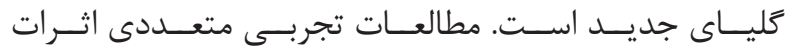

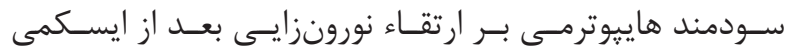

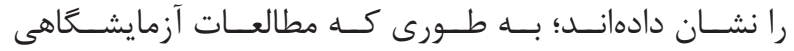

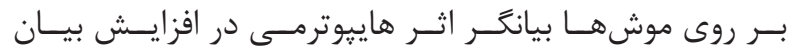

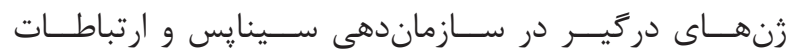

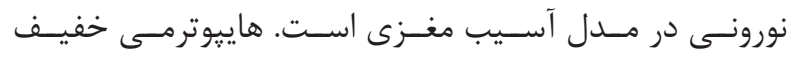

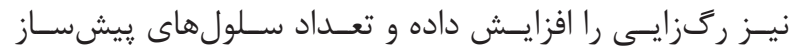

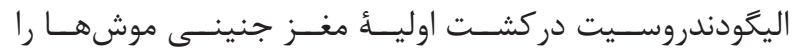

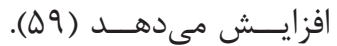

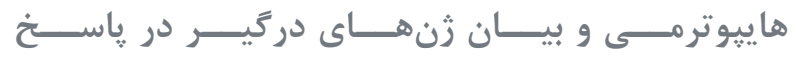

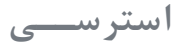

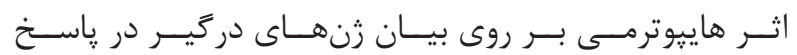

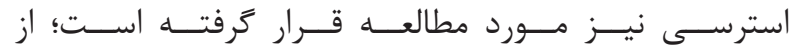

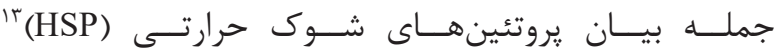

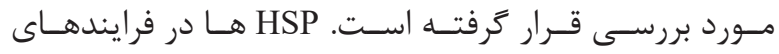

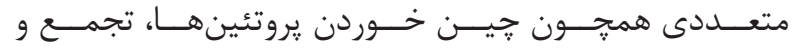

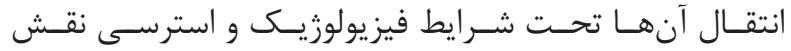

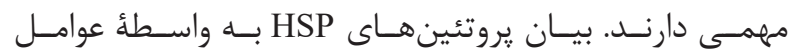

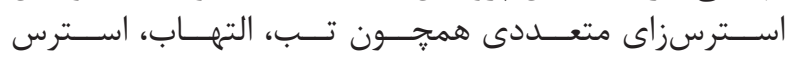

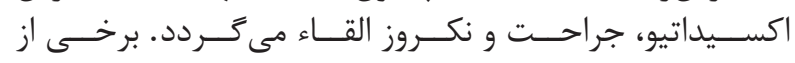

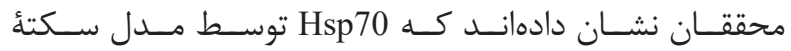

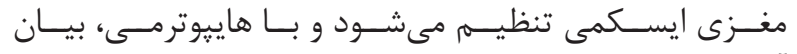

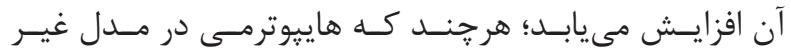

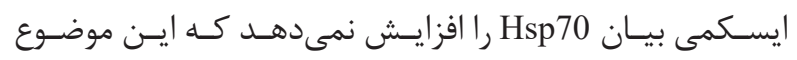

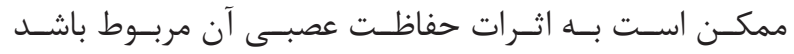

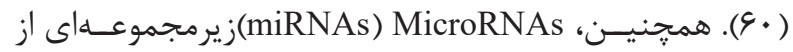

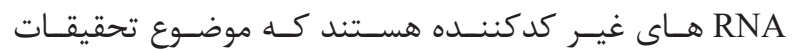

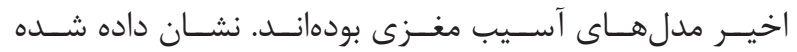

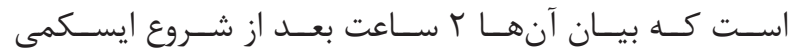

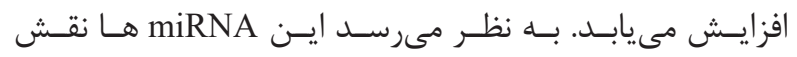

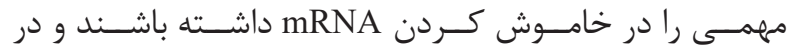

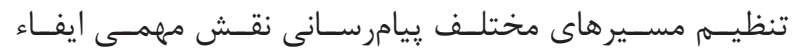

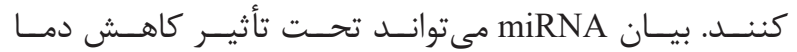

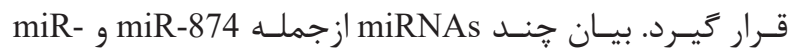

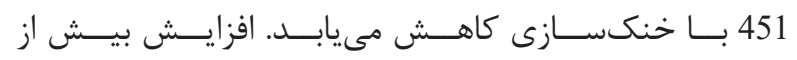

${ }^{8}$ Ionotropic glutamate receptor 2

${ }^{9} \alpha$-Amino-3-hydroxy-5-methyl-4-isoxazole propionic acid

${ }^{10}$ Gamma-aminobutyric acid
كاهـش سـرعت ســوخت و ســاز و تحريـــ مصــرف كلوكـز،

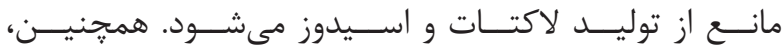

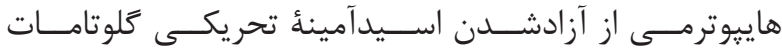

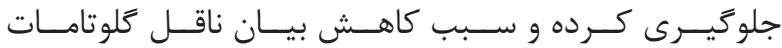

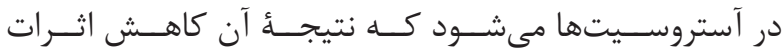

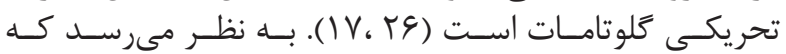

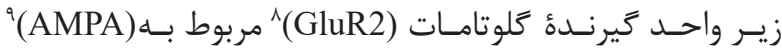

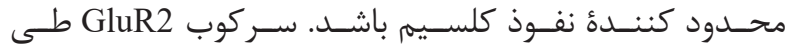

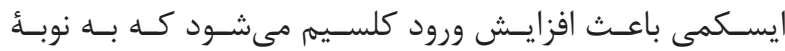

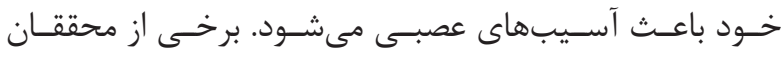

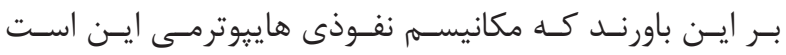

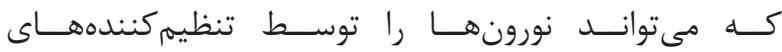

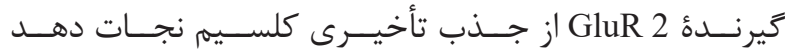

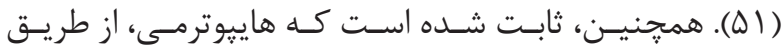

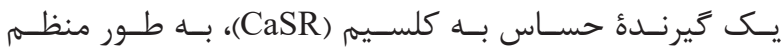

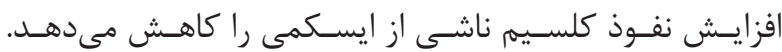

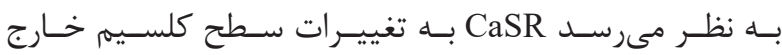

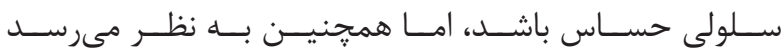

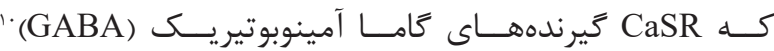

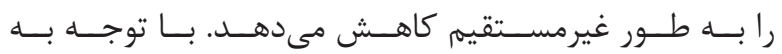

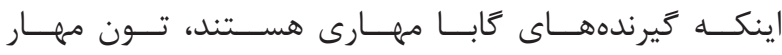

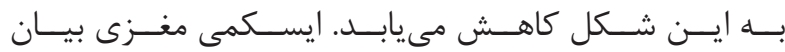

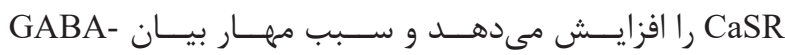

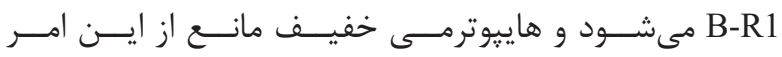

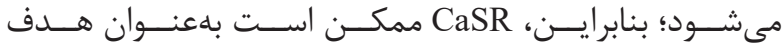

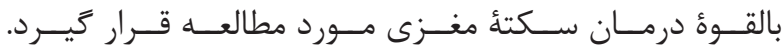

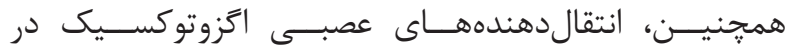

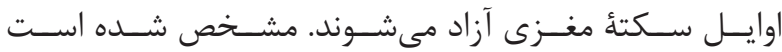

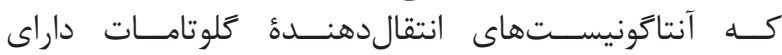

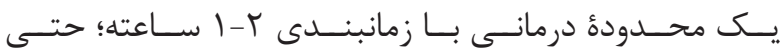

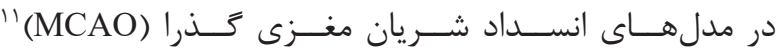

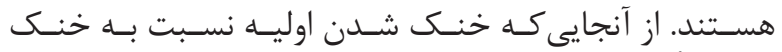

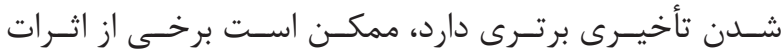

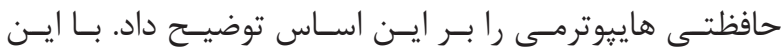

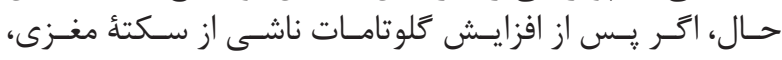

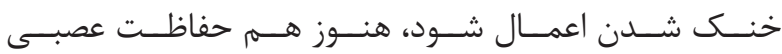

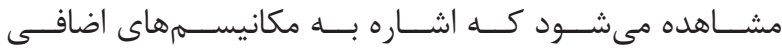

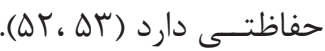

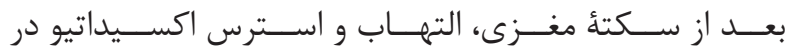

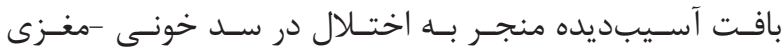

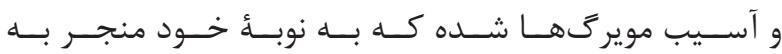

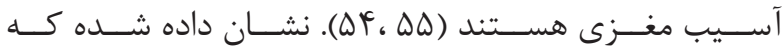

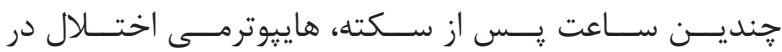

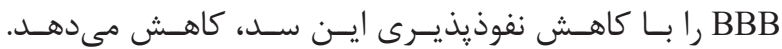

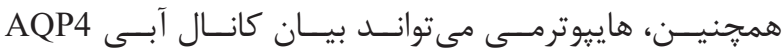

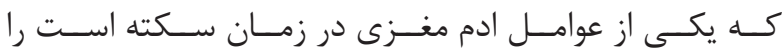

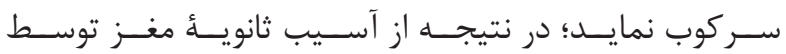

${ }^{11}$ Middle cerebral artery occlusion

${ }^{12}$ Neurogenesis

${ }^{13}$ Heat shock protein 


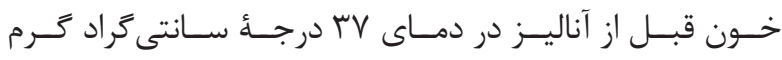

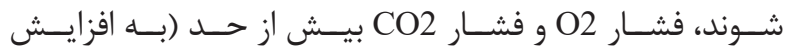

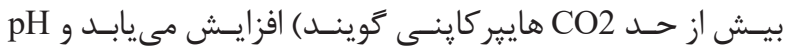

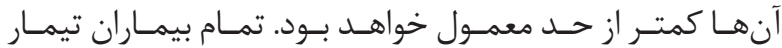

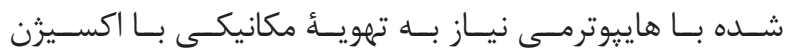

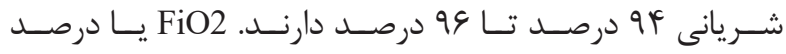

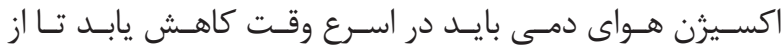

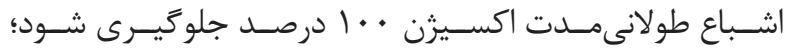

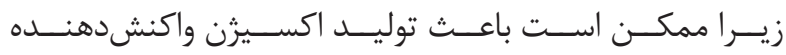

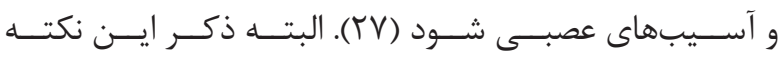

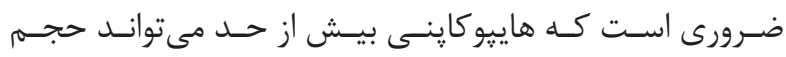

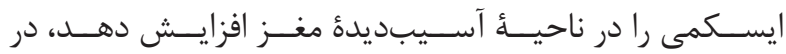

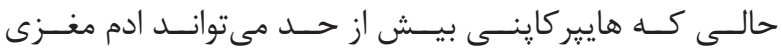

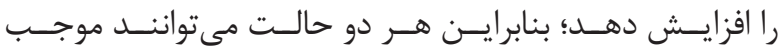

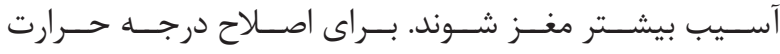

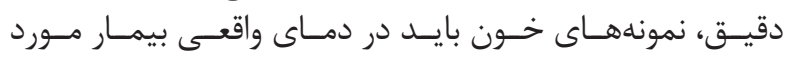

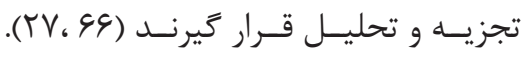

$$
\text { هاييوتر مى و پاسخخهاى التهابى }
$$

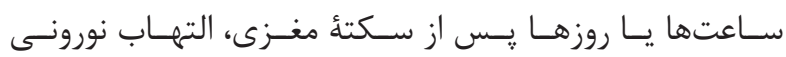

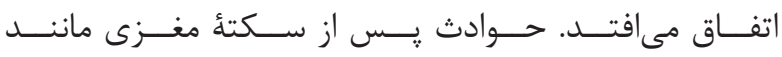

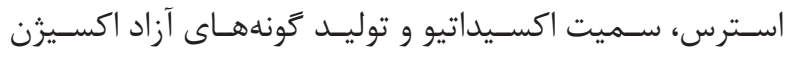

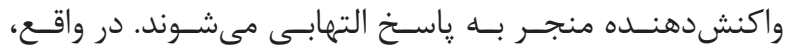

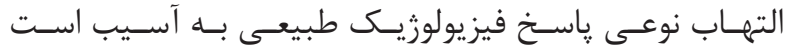

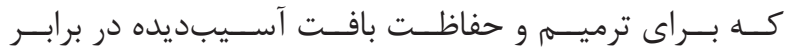

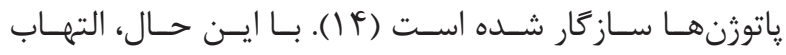

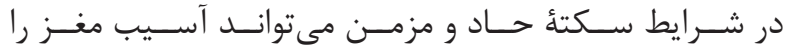

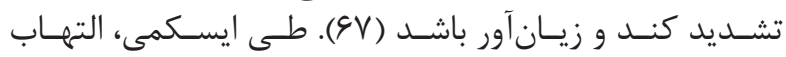

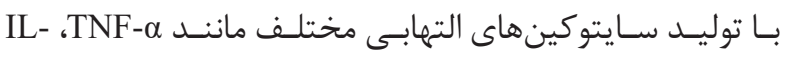

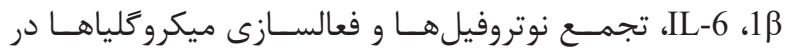

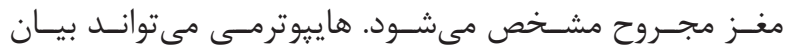

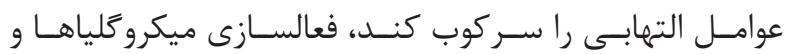

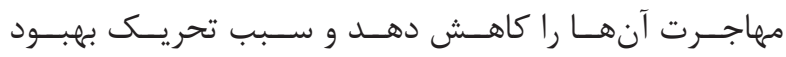

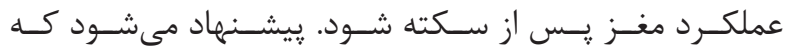

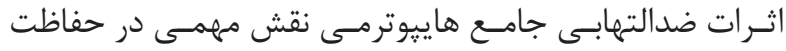

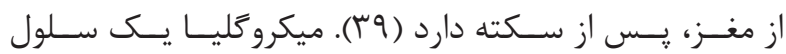

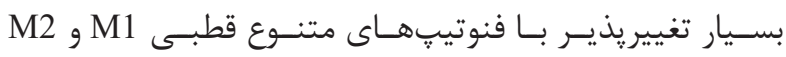

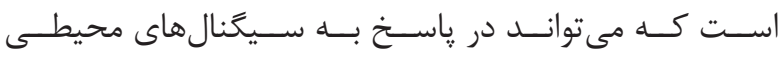

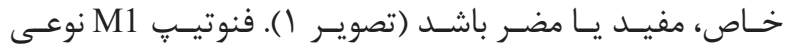

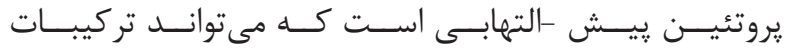

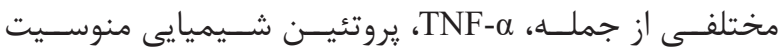
(CCL2 / MCP-1) و نيتر يك اكـسايد ســنتاز القـائى (iNOS)

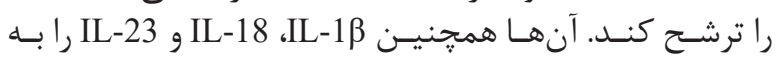

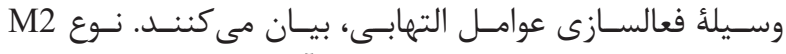

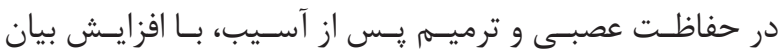

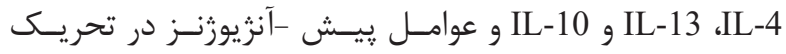

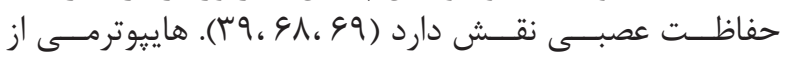

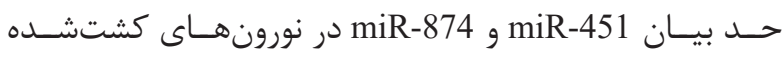

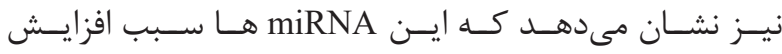

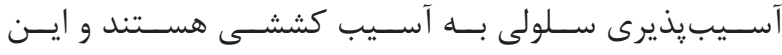

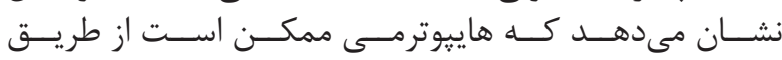

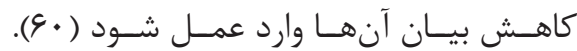

$$
\text { هاييوترمى و كنترل كلوكز خون }
$$

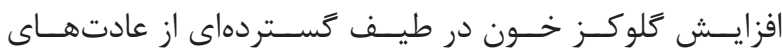

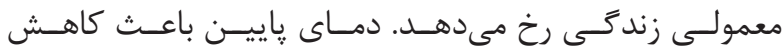

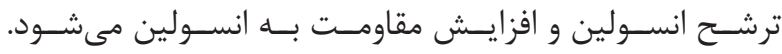

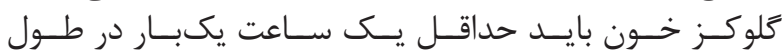

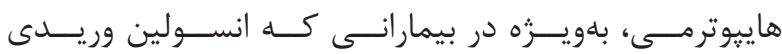

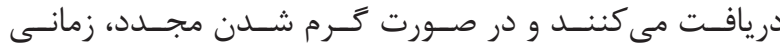

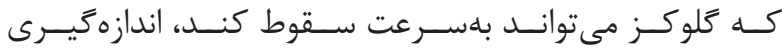

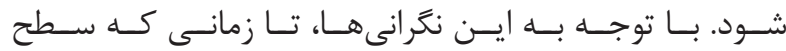

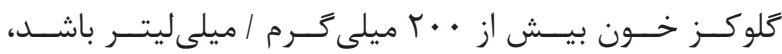

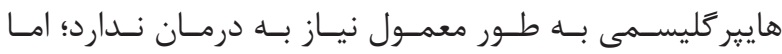

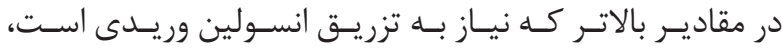

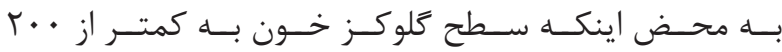

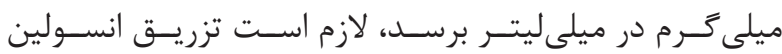

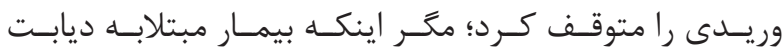

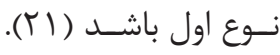

$$
\text { هاييوتر مى و سطوح الكتروليتهاى سرم }
$$

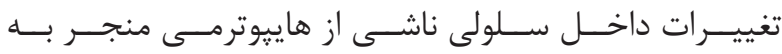

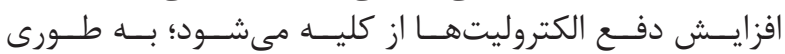

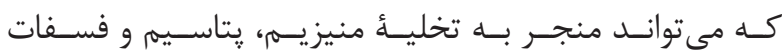

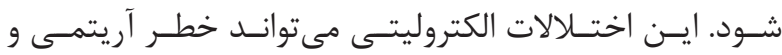

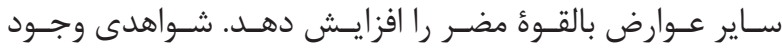

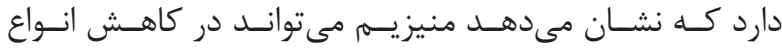

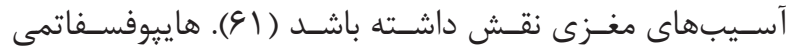

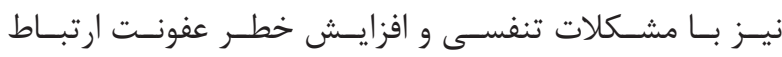

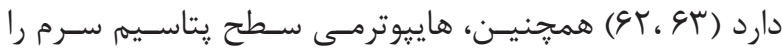

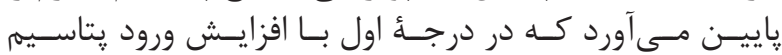

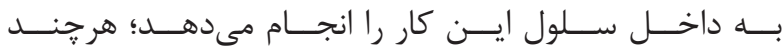

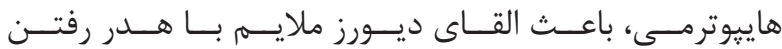

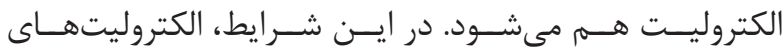

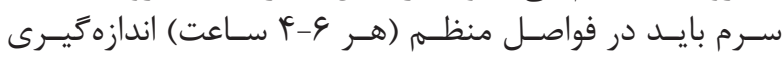

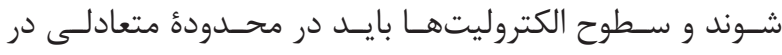

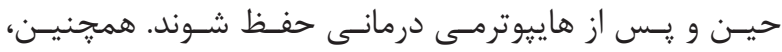

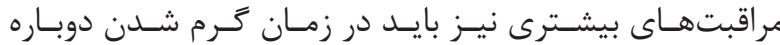

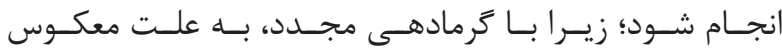

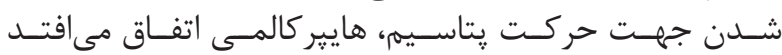

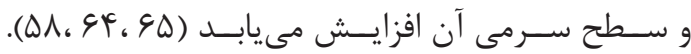

$$
\text { هاييوترمى و سطوح تاز هاى خونى }
$$

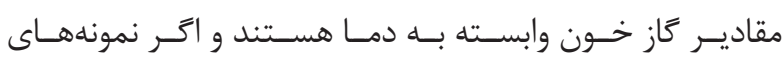

${ }^{14}$ Induced Nitric oxide syntetase 


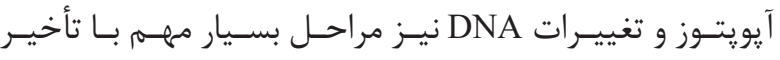

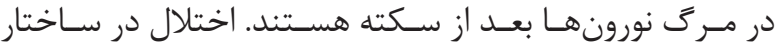

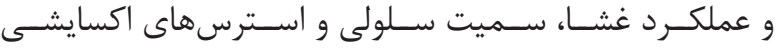

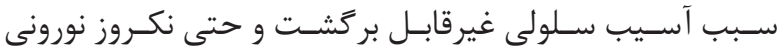

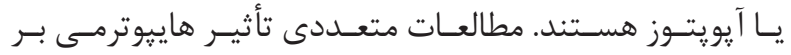

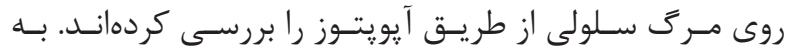

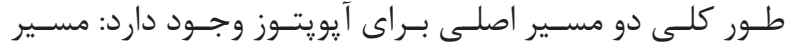

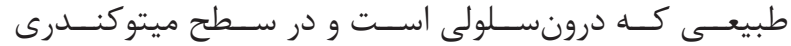

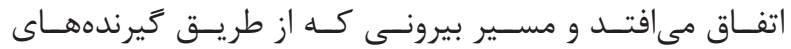

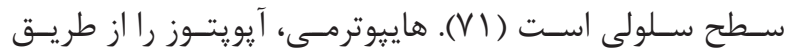

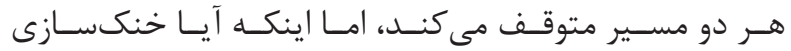

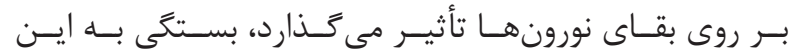

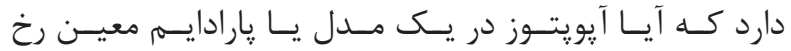

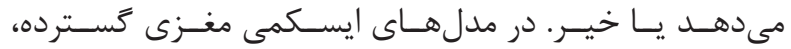

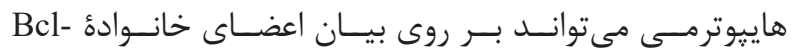

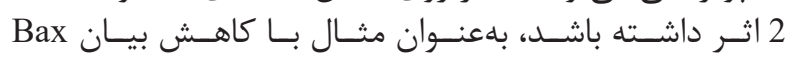

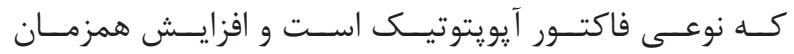

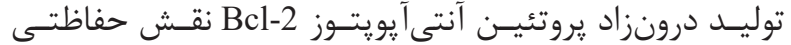

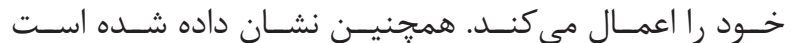

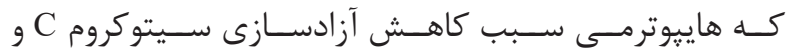

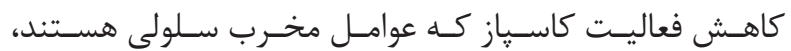

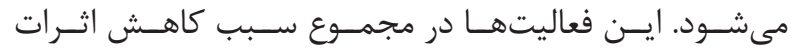

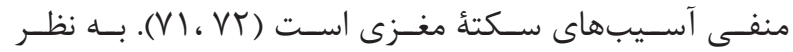

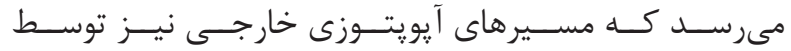

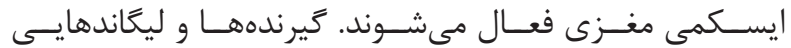

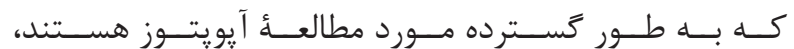

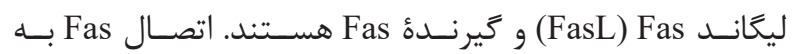

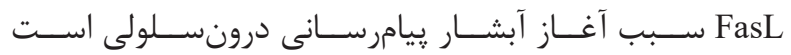

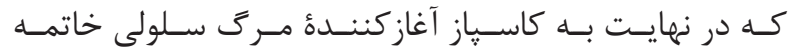

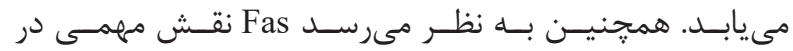

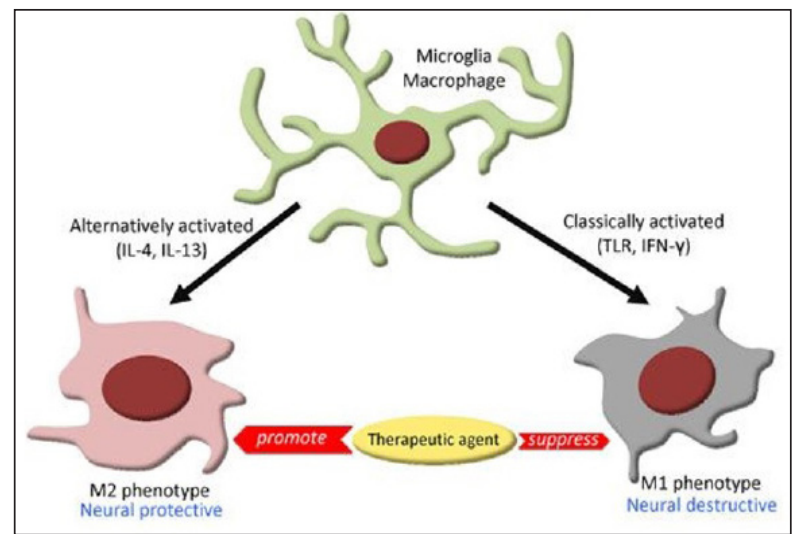

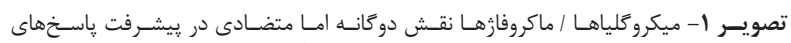

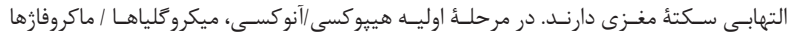

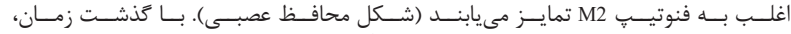

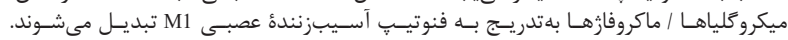

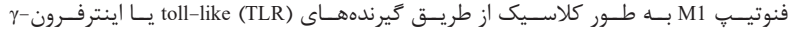

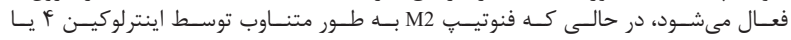

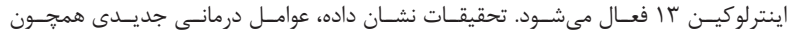

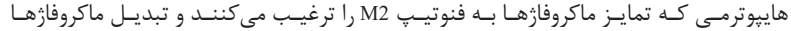

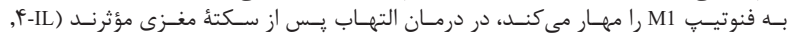
.(99)-((interleukin 4; IL-13, interleukin 13; TLR, toll-like receptor; IFN- $\gamma$, interferon- $\gamma$

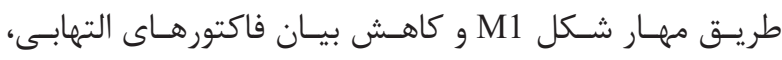

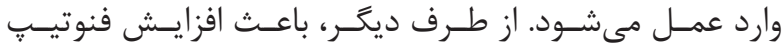

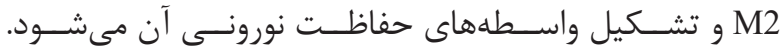

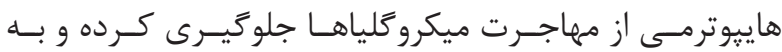

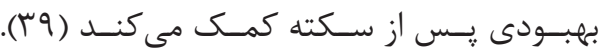

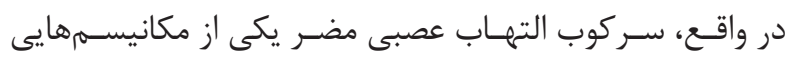

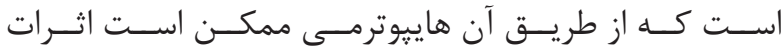

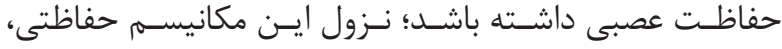

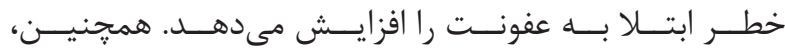

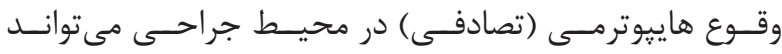

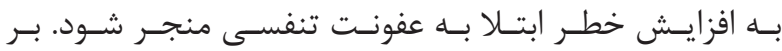

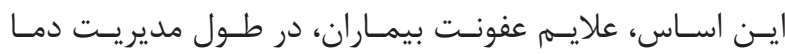

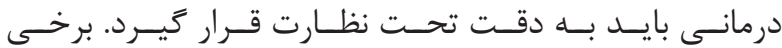

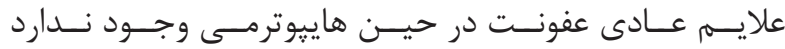

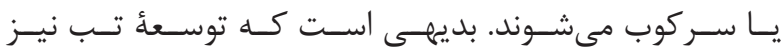

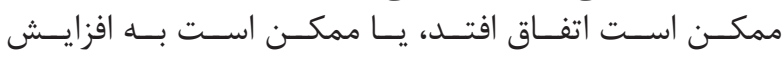

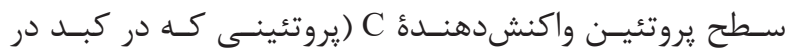

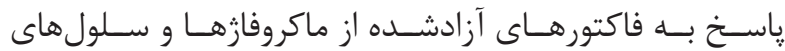

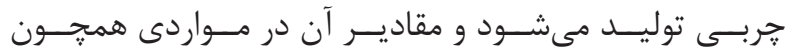

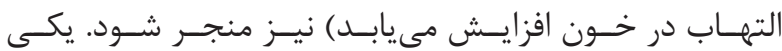

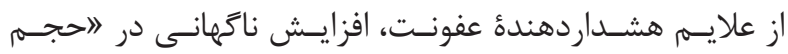

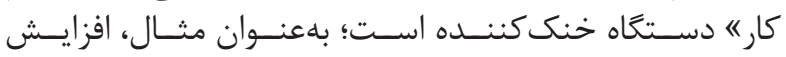

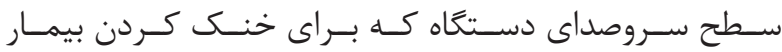

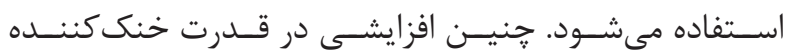

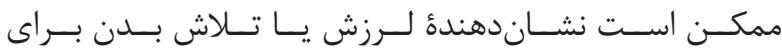

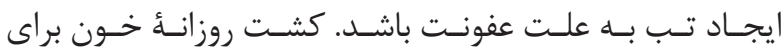

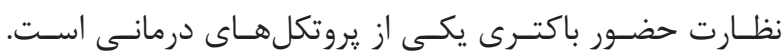

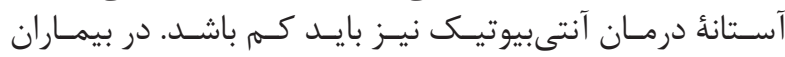

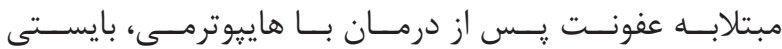

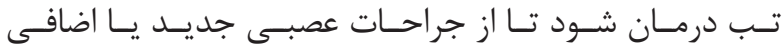
جلوكيــرى شـود (rV،V.

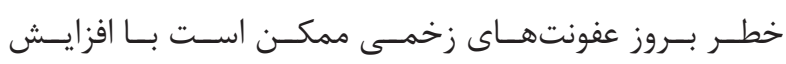

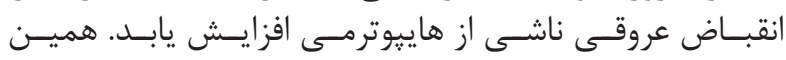

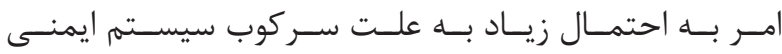

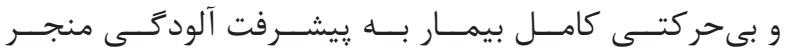

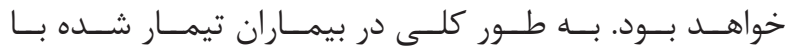

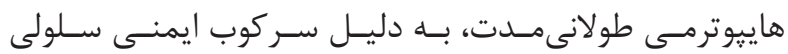

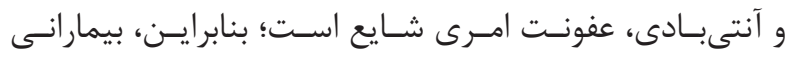

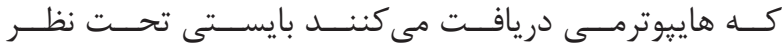

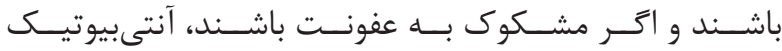

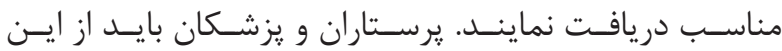

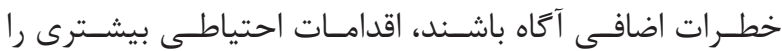

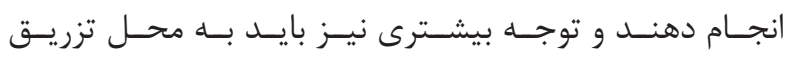

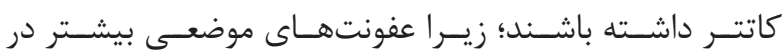

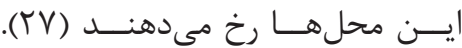

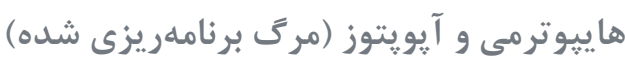




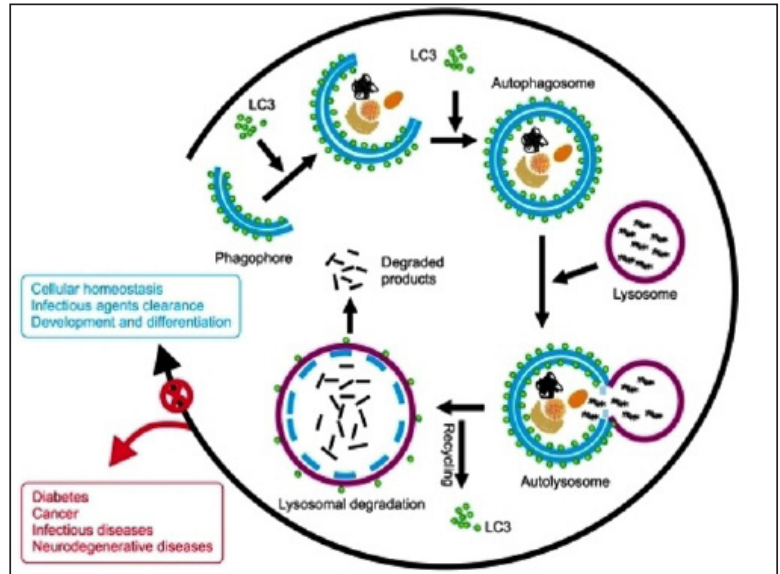

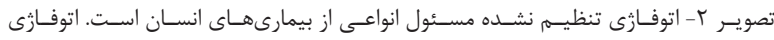

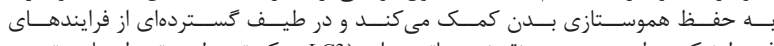

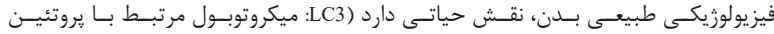

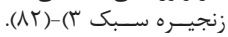

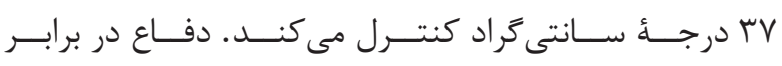

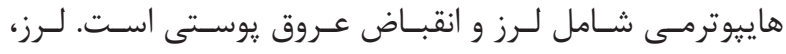

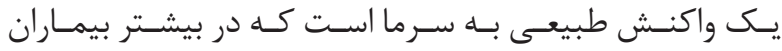

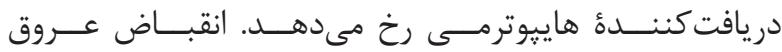

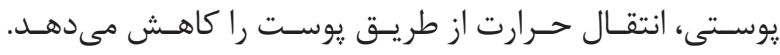

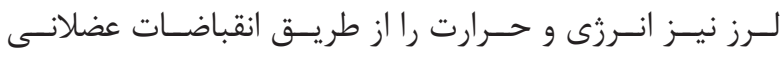

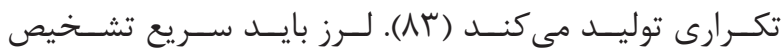

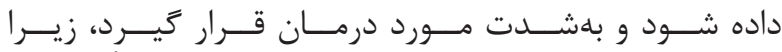

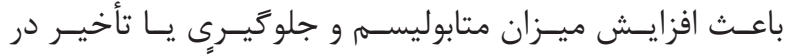

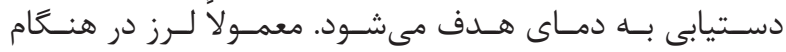

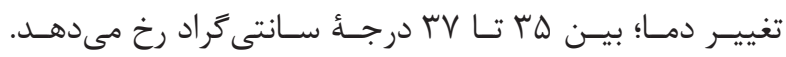

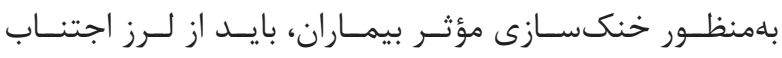

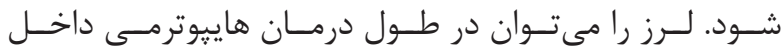

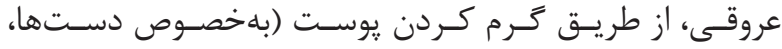

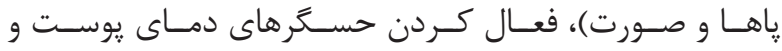

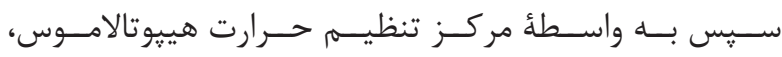

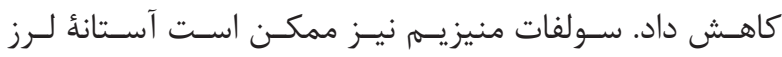

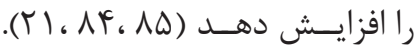

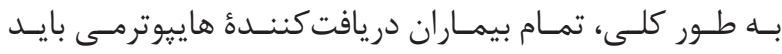

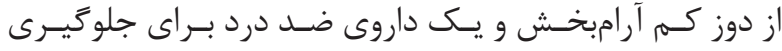

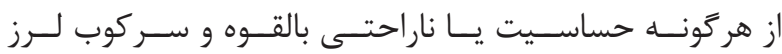

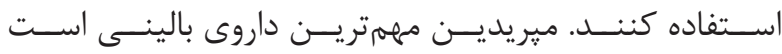

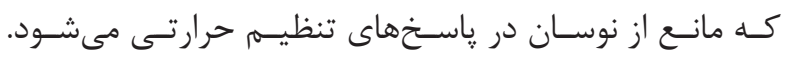

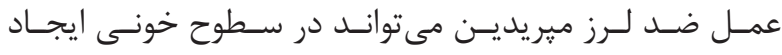

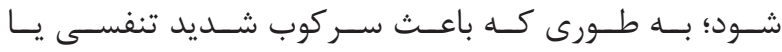

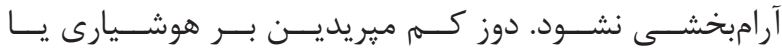

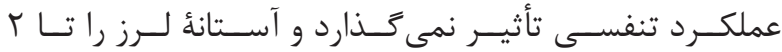

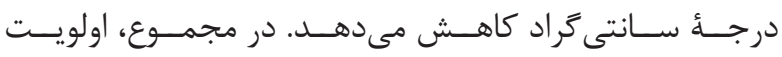

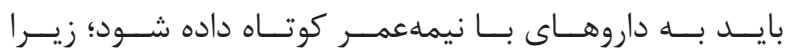

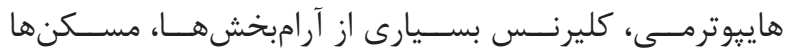

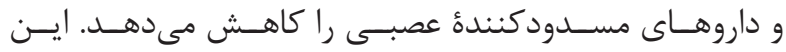

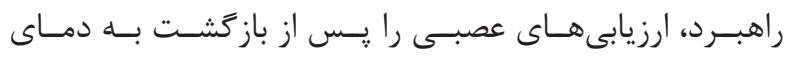

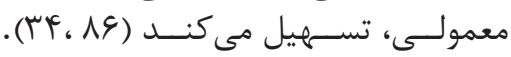

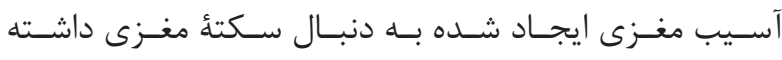

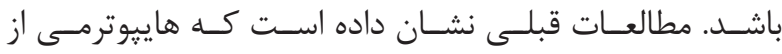

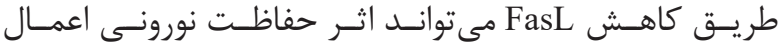

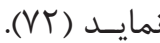

ارتباط هاييوتر مى با اتوفازى و حفاظت عصبى

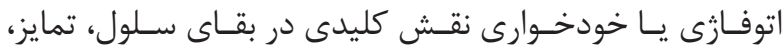

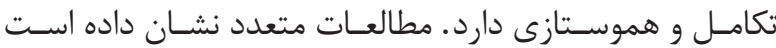

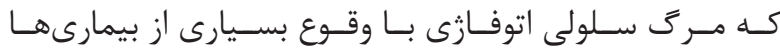

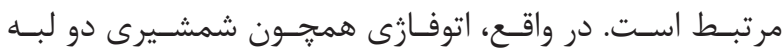

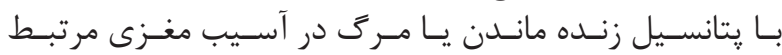

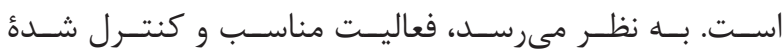

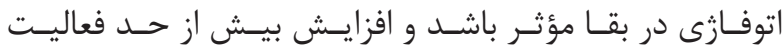

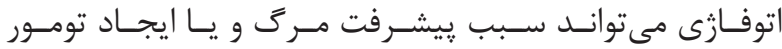

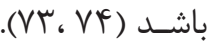

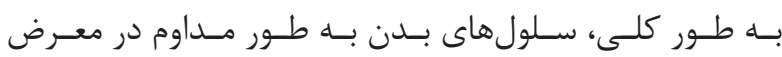

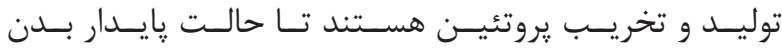

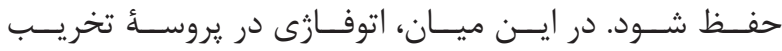

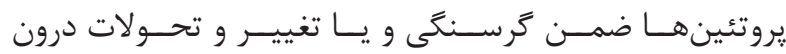

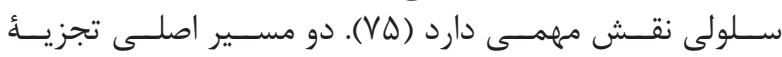

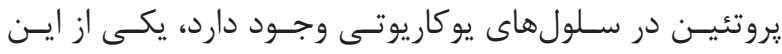

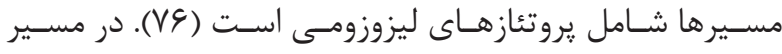

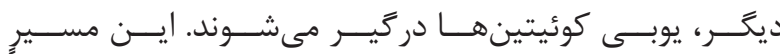

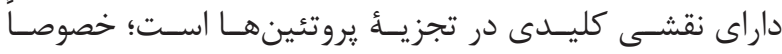

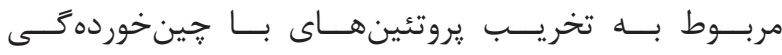

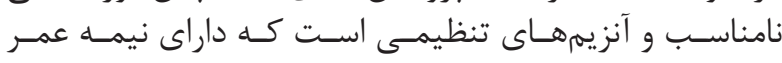

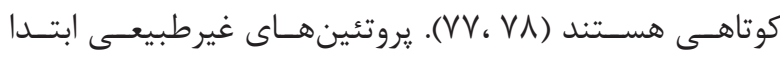

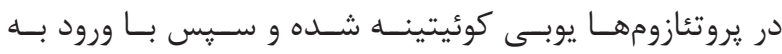

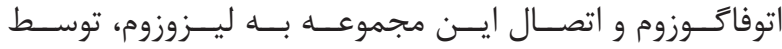

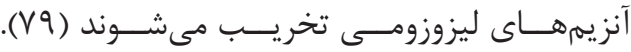

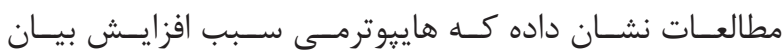

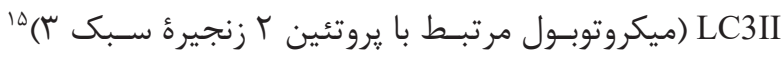

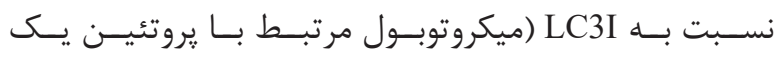

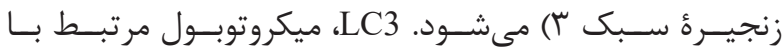

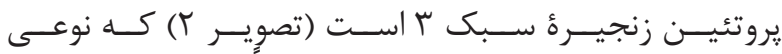

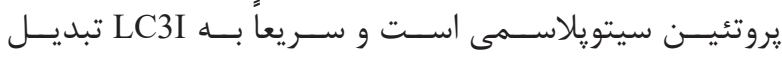

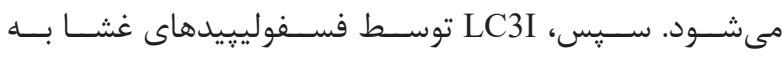

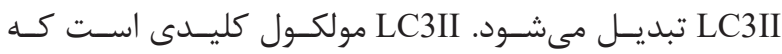

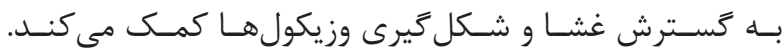

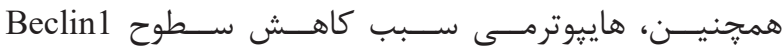

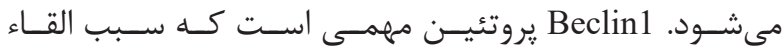

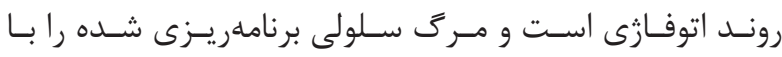

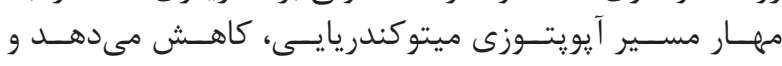

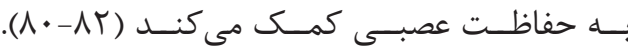
هاييوترمى و لرز سيسـتم كَرمايشـى بـــن، دقيقـاً دمــاى بــدن را در حسـدود 


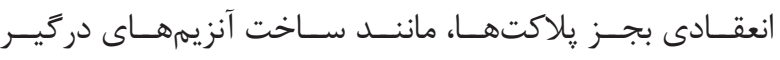

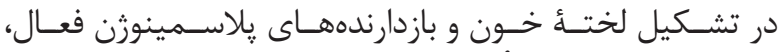

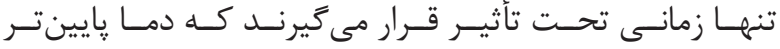

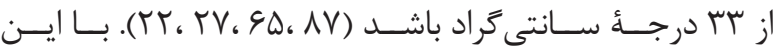

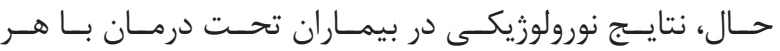

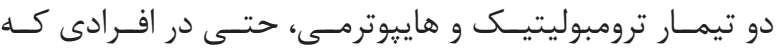

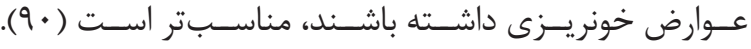

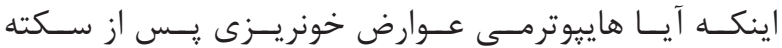

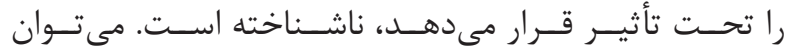

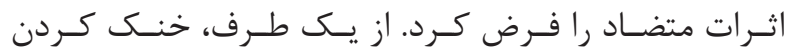

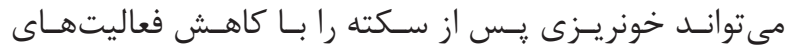

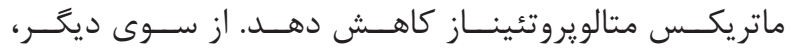

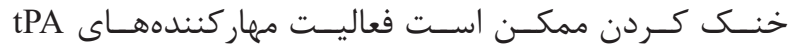

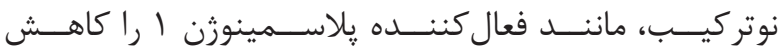

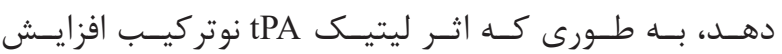

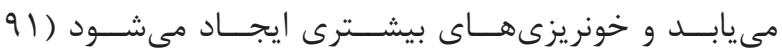

(r)، VT.

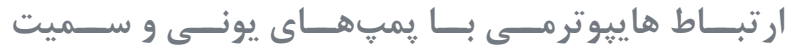

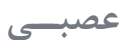

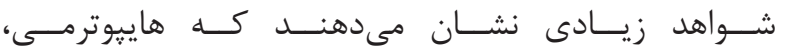

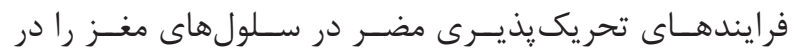

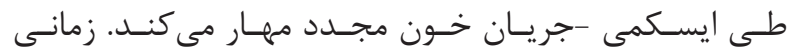

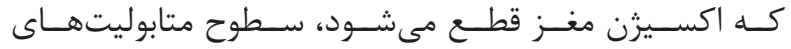

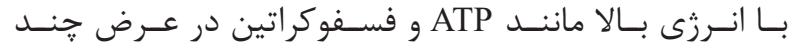

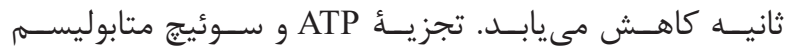

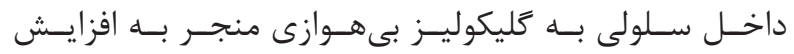

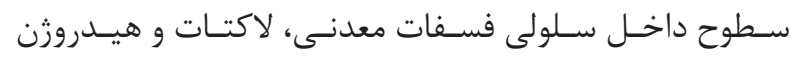

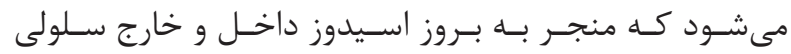

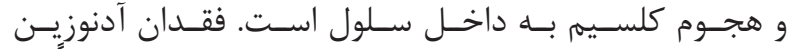

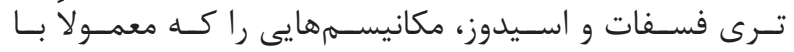

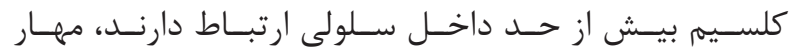

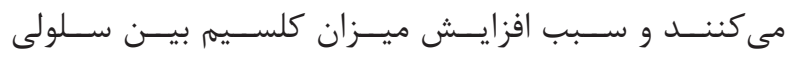

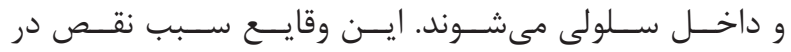

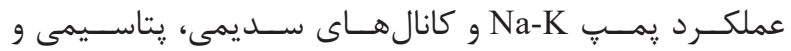

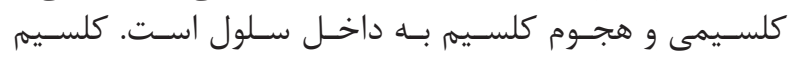

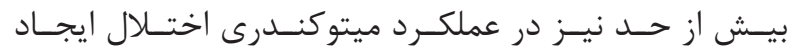

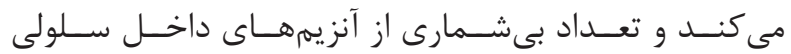

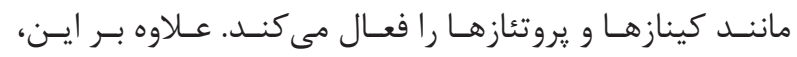

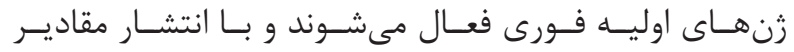

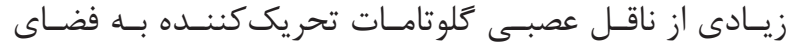

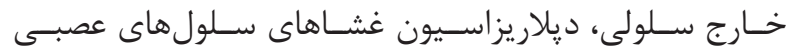

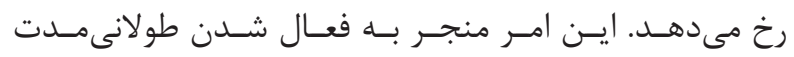

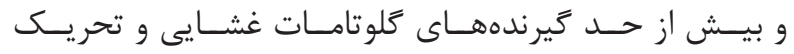

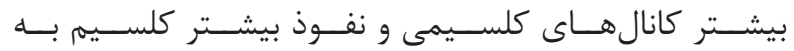

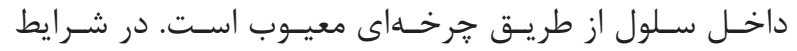

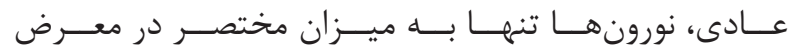

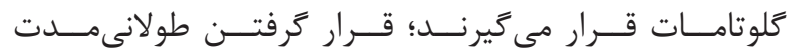

هاييوتر مى و كليرنس داروها

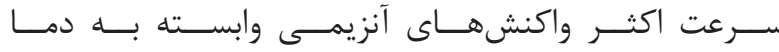

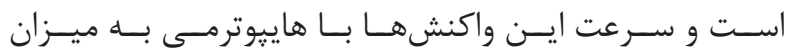

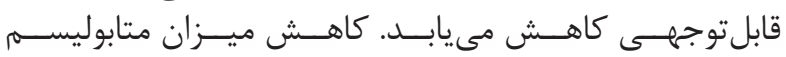

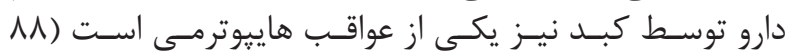

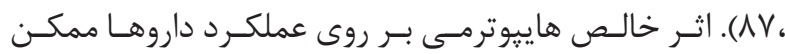

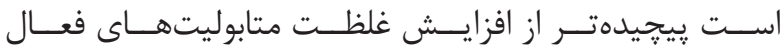

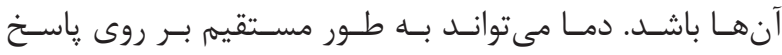

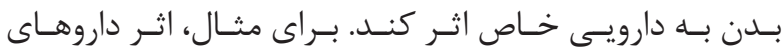

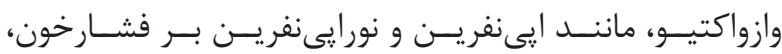

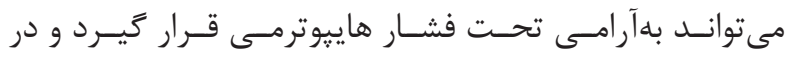

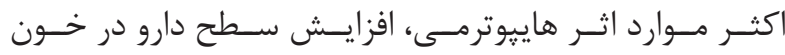

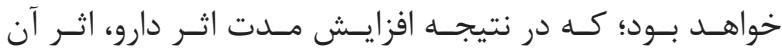

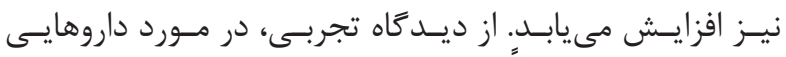

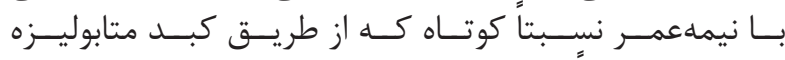

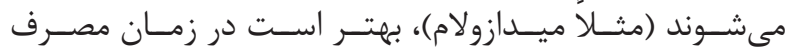

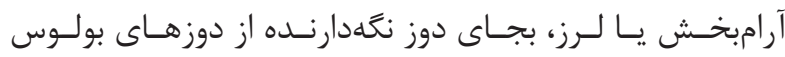

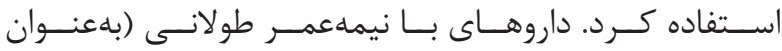

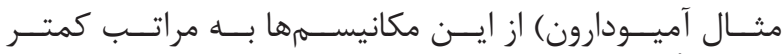

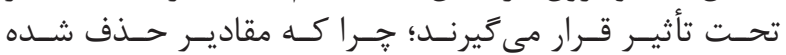

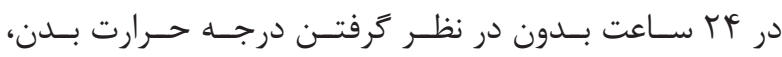

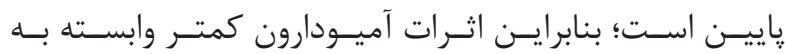

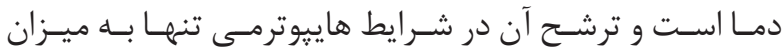

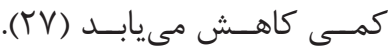
هاييوتر مىى و ترومبوليز

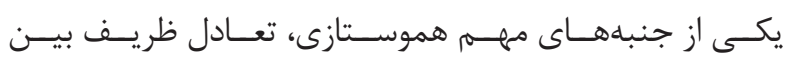

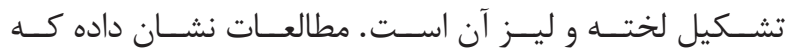

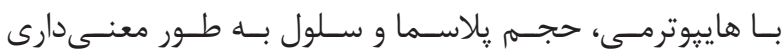

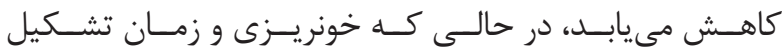

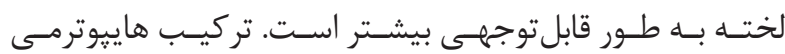

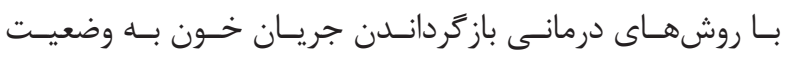

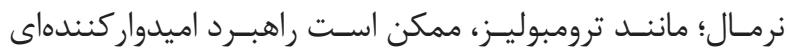

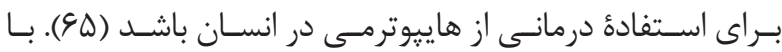

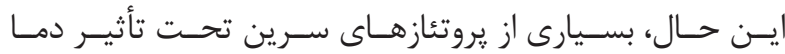

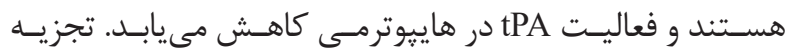

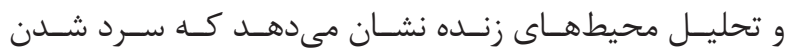

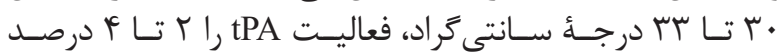

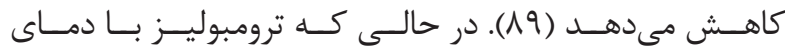

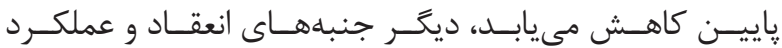

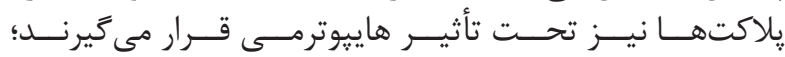

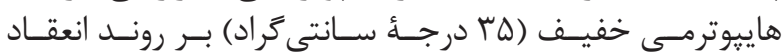

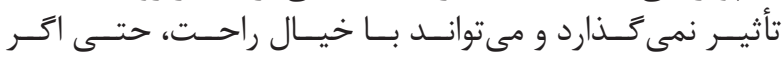

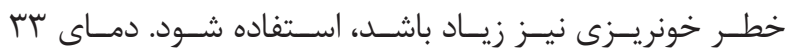

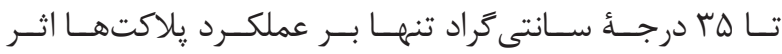

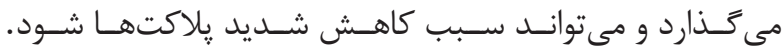

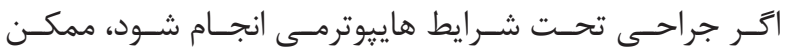

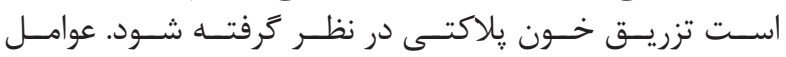




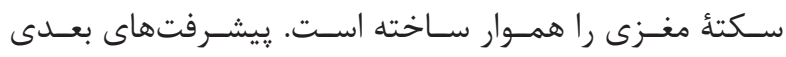

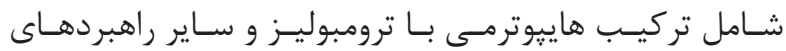

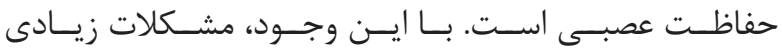

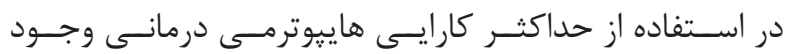

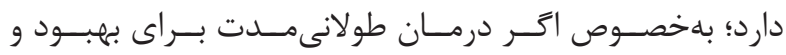

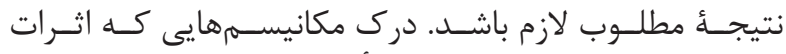

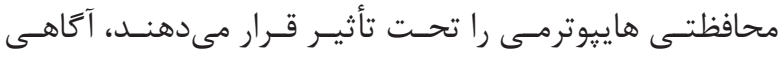

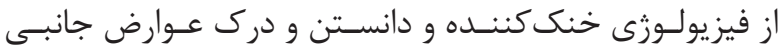

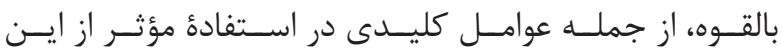

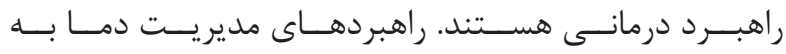

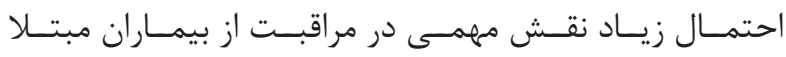

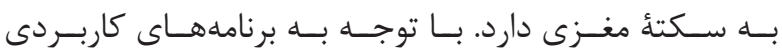

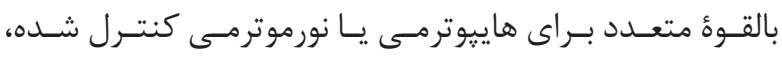

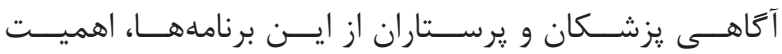

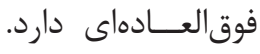

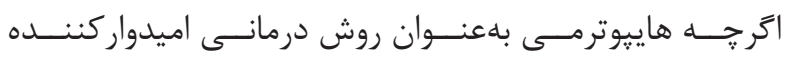

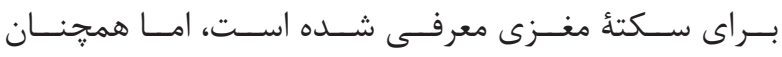

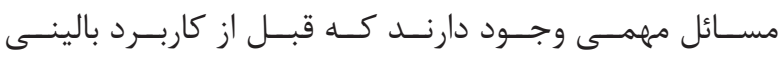

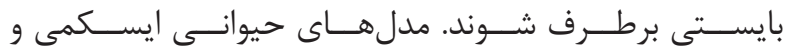

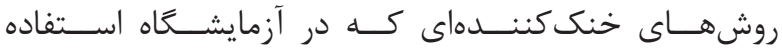

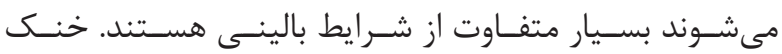

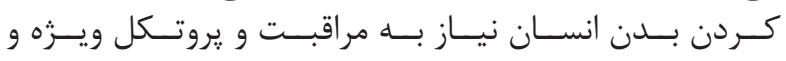

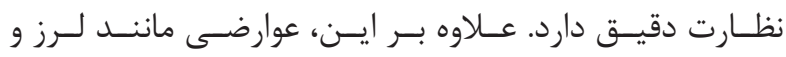

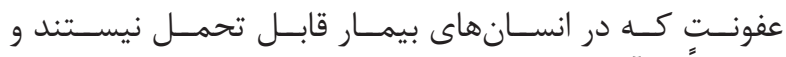

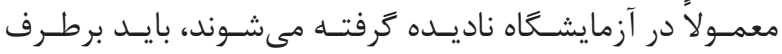

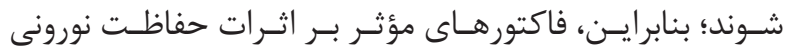

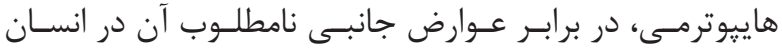

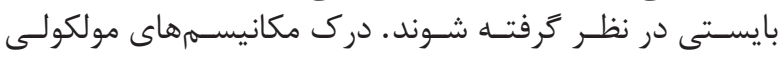

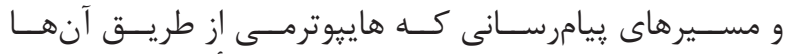

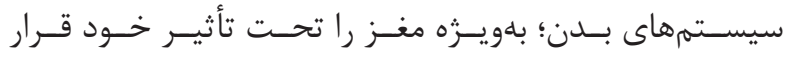

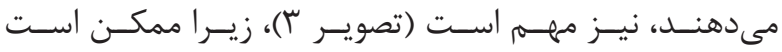

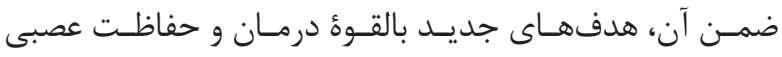

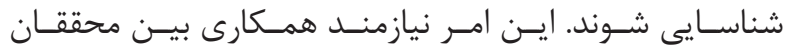

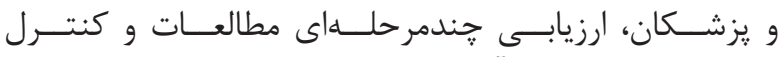

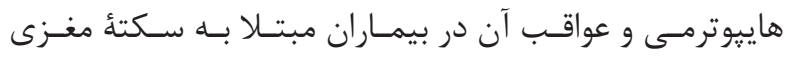

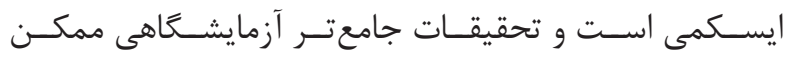

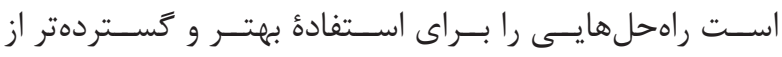

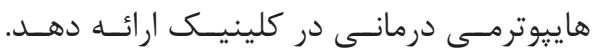

$$
\text { تشكر و قدردانى }
$$

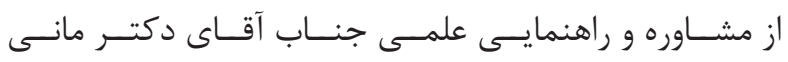

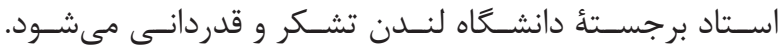

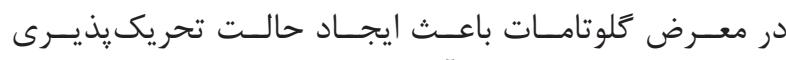

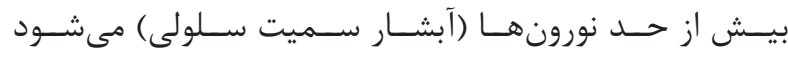

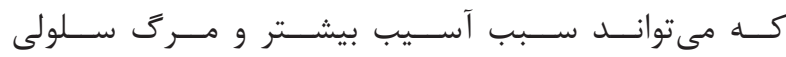

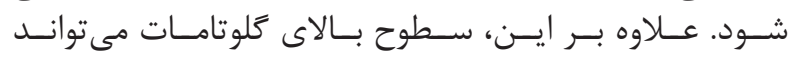

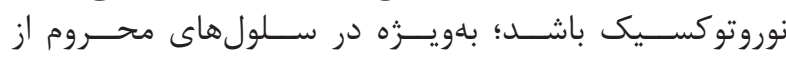

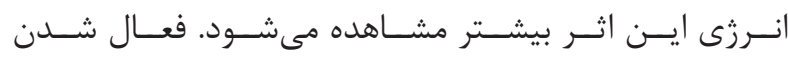

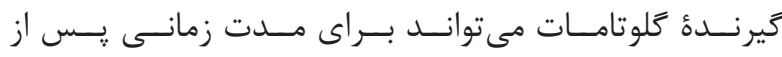

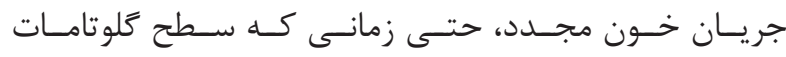

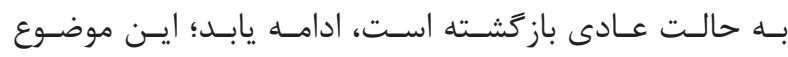

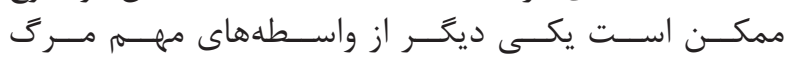

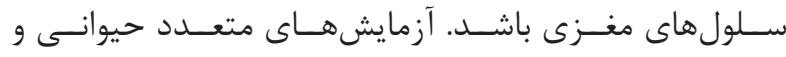

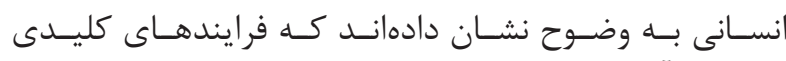

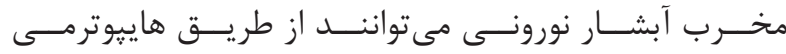

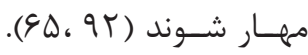
ترم كردن مجدد

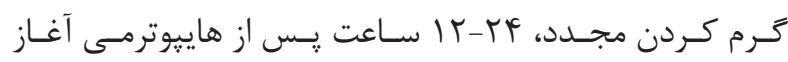

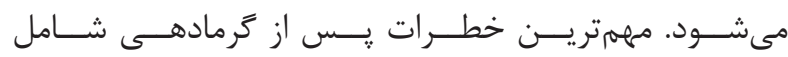

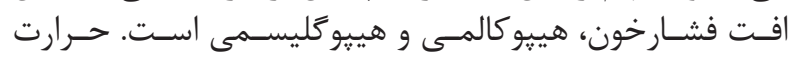

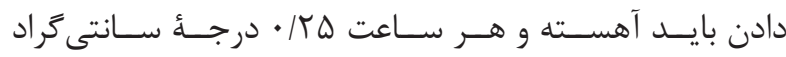

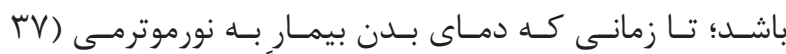

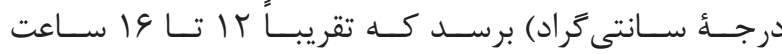

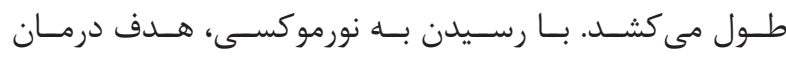

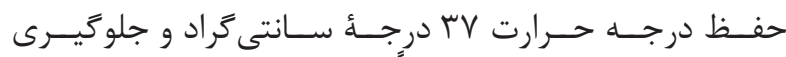

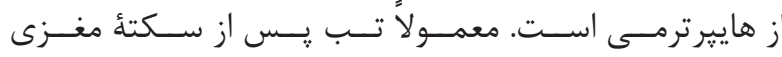

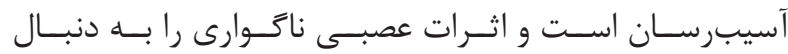

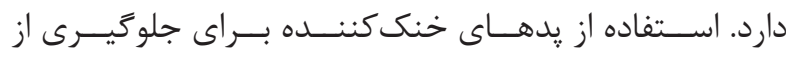

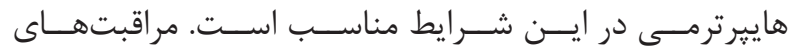

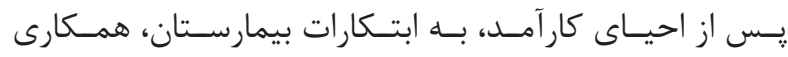

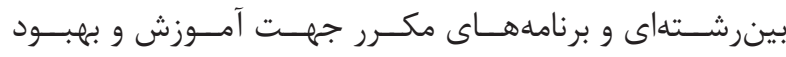

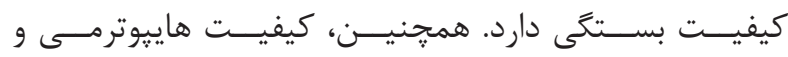

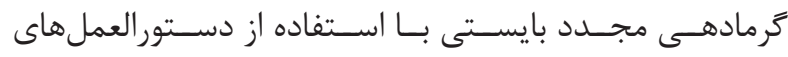

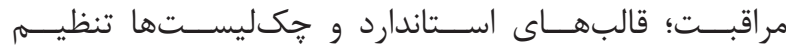
شـــند. نتيجه

راهبردهــاى حفاظـت عصبـى بعـد از سـكته مغـزىى، زمينــاى

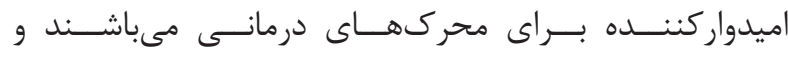

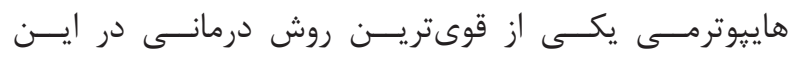

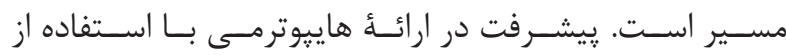

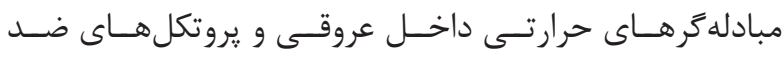

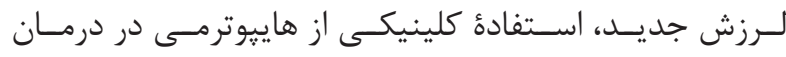



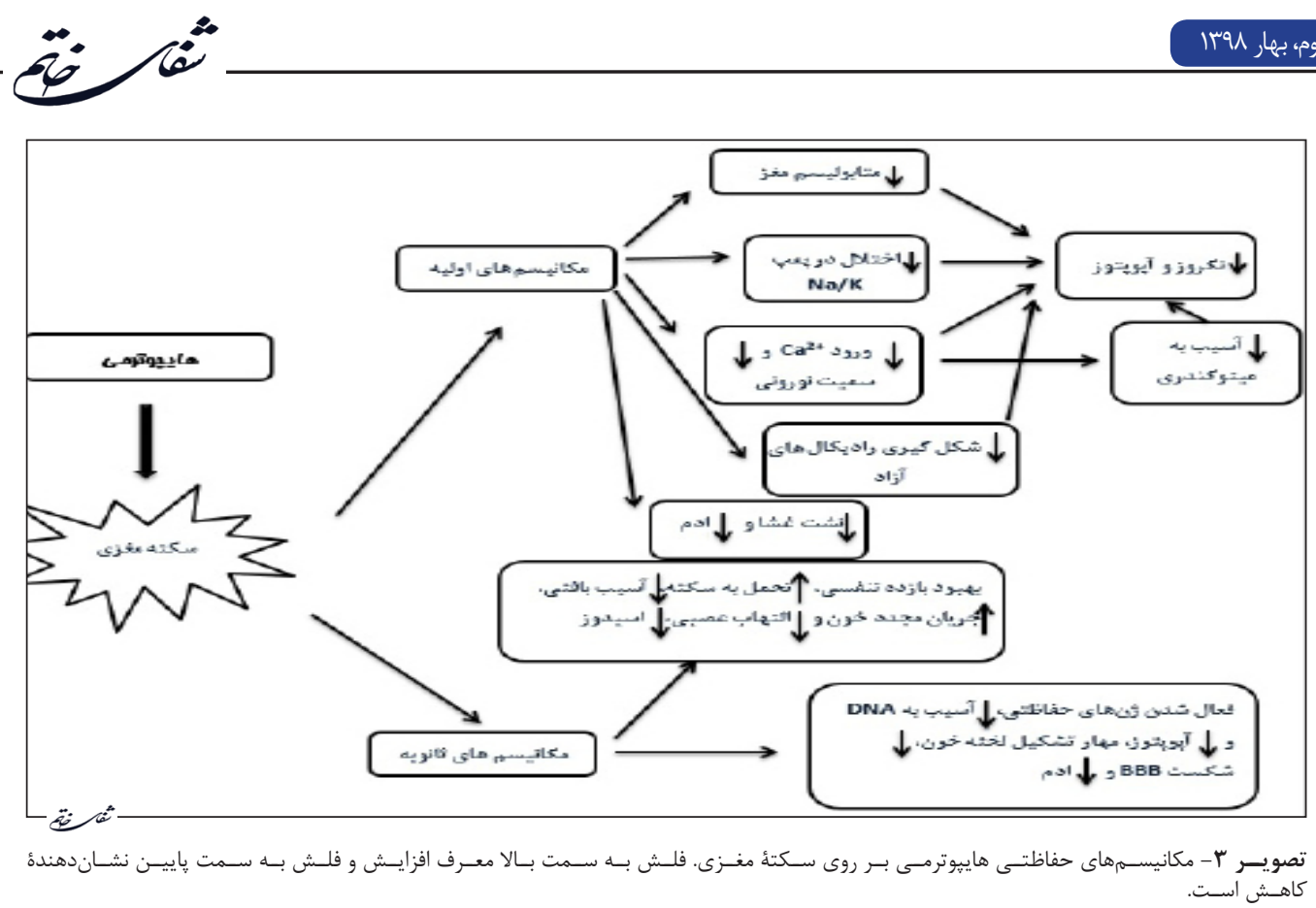

منابع

1. Hajizadeh S, Javan M, Bigdeli M, Alavian F. Evaluation of HIF expression in ischemic tolerance induced by intermittent normobaric hyperoxia in the rat model of stroke. Journal of Sabzevar University of Medical Sciences. 2012; 19(3): 287-95.

2. Astrup J, Siesjö BK, Symon L. Thresholds in cerebral ischemia-the ischemic penumbra. stroke.1981; 12(6): 723-5.

3. Hosseini SV, Rahnema M, Bigdeli MR. Effect of pre-nutrion of flax seed oil (linum usitatissimum) on the amount of cerebral ischemic lesion and motor nerve disorders in animal model rat. Armaghan-eDanesh.2015; 20(7): 558-71.

4. Alavian F, Hajizadeh S, Bigdeli MR, Bayat GR, Javan M. Evaluation of UCP 2 expression in the phenomenon of ischemic resistance induced by alternating normobaric hyperoxia in a rat model of stroke. J Physiol Pharmacol. 2012; 16(1): 54-61.

5. Patel MD, Tilling K, Lawrence E, Rudd AG, Wolfe CDA, McKevitt C. Relationships between longterm stroke disability, handicap and health-related quality of life. Age Ageing. 2006; 35(3): 273-9.

6. Rahnema M, Ghasemloo E, Foroozandeh M. The neuroprotective effect of hydroalcoholic extract of satureja hortensis on infarct volume and neurologic deficits in rat stroke model. Armaghan-e-Danesh. 2015; 20(9): 799-810.

7. Mohebbi S, Ghabaee M, Ghaffarpour M, Meisami Ap, Shahsiah R, Mousavi Mirkola M, et al. Creactive portein predicting role for mortality after ischemic stroke. Shefaye Khatam. 2013; 1(3): 6-11.
8. Sahraeian S, Edalatmanesh MA. The neuroprotective effect of sodium butyrate on short-term memory and serum level of b-cell lymphoma 2 in a rat model of cerebral hypoxic-ischemia. Shefaye Khatam. 2018; 6(1): 34-40.

9. Alavian F, Haizadeh S. Cognitive disorders resulting from stroke. Advances in Cognitive Science. 2018; 20(3): 15-33.

10. Alavian F, Ghiasvand S. Protective effects of jujube extract against permeability of bloodbrain barrier, and the activity of glutathione peroxidase and catalase in stroke model. Journal of Isfahan Medical School. 2018; 36(475): 379-85.

11. Delbari A, Salman-Roghani R, Tabatabae SS. Stroke rehabilitation: principles, advances, early experiences, and realities in iran. Journal of Sabzevar University of Medical Sciences. 2012; 19(2): 96-108.

12. Fonarow GC, Smith EE, Saver JL, Reeves MJ, Bhatt DL, Grau-Sepulveda MV, et al. Timeliness of tissuetype plasminogen activator therapy in acute ischemic strokeclinical perspective. Circulation. 2012; 123(7): 750-8.

13. Alavian F, Hajizadeh S, Javan M, Mazloom R. Evaluation of ERK activity on ischemic toleranceinduced by preconditioning with intermittent normobaric hyperoxia in the rat model of stroke. Arak Medical University Journal (AMUJ). 2017; 20(123): 53-41.

14. Alavian F, Hajizadeh S, Javan M, Bigdeli MR. Effects of preconditioning with intermittent normobaric hyperoxia on TNFR 1 and TNFR 2 expression in the rat brain. J Physiol Pharmacol. 2017; 21(2): 110-9. 
15. Naderi S, Ali Mohammadi R, Shamsi Zadeh A, Mobini M, Amin F, Allahtavakoli M. The effect of exercise preconditioning on stroke outcome in an experimental mice model. Shefaye Khatam. 2015; 3(3): 45-53.

16. Shobha N, Buchan AM, Hill MD; Canadian Alteplase for Stroke Effectiveness Study (CASES). Thrombolysis at 3-4.5 hours after acute ischemic stroke onset-evidence from the canadian alteplase for stroke effectiveness study (CASES) registry. Cerebrovasc Dis. 2016; 31(3): 223-8.

17. Lyden PD, Krieger D, Yenari M, Dietrich WD. Therapeutic hypothermia for acute stroke. Int J Strok. 2006; 1(1): 9-19.

18. Reith J, Jorgensen HS, Pedersen PM, Nakamaya H, Jeppesen LL, Olsen TS, et al. Body temperature in acute stroke: relation to stroke severity, infarct size, mortality, and outcome. Lancet. 1996; 347(8999): 422-5.

19. Iadecola C, Anrather J. Stroke research at a crossroad: asking the brain for directions. Nat Neurosci. 2011; 14(11): 1363-8.

20. Merrill L. Therapeutic hypothermia to treat hypoxic ischemic encephalopathy in newborns. Nurs Womens Health. 2012; 16(2): 126-34.

21. Sidhu SS, Schulman SP, McEvoy JW. Therapeutic hypothermia after cardiac arrest. Journal of Current Treatment Options In Cardiovascular Medicine. 2016; 18(5): 1-12.

22. Poblete R, Sung G. Hypothermia for acute ischemic stroke. Neuroprotective Therapy for Stroke and Ischemic Disease: Springer; 2017; p. 477-99.

23. Wu T-C, Grotta JC. Hypothermia for acute ischaemic stroke. Lancet Neurol. 2013; 12(3): 275-84.

24. Goossens J, Hachimi-Idrissi S. Combination of therapeutic hypothermia and other neuroprotective strategies after an ischemic cerebral insult. Curr Neuropharmacol. 2014; 12(5): 399-412.

25. Ikonomidou C, Mosinger JL, Olney JW. Hypothermia enhances protective effect of MK-801 against hypoxic/ ischemic brain damage in infant rats. Brain Res. 1989; 487(1): 184-7.

26. Wang D, Zhao Y, Zhang Y, Zhang T, Shang X, Wang $\mathrm{J}$, et al. Hypothermia protects against oxygen-glucose deprivation-induced neuronal injury by down-regulating the reverse transport of glutamate by astrocytes as mediated by neurons. Neuroscience. 2013; 237: 130-8.
27. Polderman KH. Mechanisms of action, physiological effects, and complications of hypothermia. Crit Care Med. 2009; 37(7): S186-S202.

28. Schwab S, Schwarz S, Spranger M, Keller E, Bertram M, Hacke W. Moderate hypothermia in the treatment of patients with severe middle cerebral artery infarction. Stroke. 1998; 29(12): 2461-6.

29. Polderman KH, Noc M, Beishuizen A, Biermann H, Girbes ARJ, Tully GW, et al. Ultrarapid induction of hypothermia using continuous automated peritoneal lavage with ice-cold fluids: final results of the cooling for cardiac arrest or acute ST-elevation myocardial infarction trial. Crit Care Med. 2015; 43(10): 2191-201.

30. Dae MW, Gao DW, Ursell PC, Stillson CA, Sessler DI. Safety and efficacy of endovascular cooling and rewarming for induction and reversal of hypothermia in human-sized pigs. Stroke. 2003; 34(3): 734-8.

31. Krieger DW, Michael A, Abou-Chebl A, Andrefsky JC, Sila CA, Katzan IL, et al. Cooling for acute ischemic brain damage (cool aid): an open pilot study of induced hypothermia in acute ischemic stroke. Stroke. 2001; 32(8): 1847-54.

32. Song SS, Lyden PD. Overview of therapeutic hypothermia. Curr Treat Options Neurol. 2012; 14(6): 541-8.

33. Sessler DI. Complications and treatment of mild hypothermia. Anesthesiology. 2001; 95(2): 531-43.

34. Lyden PD, Hemmen TM, Grotta J, Rapp K, Raman R. Endovascular therapeutic hypothermia for acute ischemic stroke: ICTuS 2/3 protocol. Int J Stroke. 2014; 9(1): 117-25.

35. Campbell BCV, Mitchell PJ, Kleinig TJ, Dewey HM, Churilov L, Yassi N, et al. Endovascular therapy for ischemic stroke with perfusion-imaging selection. $\mathrm{N}$ Engl J Med. 2015; 372(11): 1009-18.

36. Hemmen TM, Lyden PD. Induced hypothermia for acute stroke. Stroke. 2007; 38(2): 794-9.

37. Orwig KS, Lassetter MR, Hadden MK, Dix TA. Comparison of N-terminal modifications on neurotensin(8-13) analogues correlates peptide stability but not binding affinity with in vivo efficacy. J Med Chem. 2009; 52(7): 1803-13.

38. Lee JH, Wei L, Gu X, Wei Z, Dix TA, Yu SP. Therapeutic effects of pharmacologically induced hypothermia against traumatic brain injury in mice. J Neurotrauma. 2014; 31(16): 1417-30. 
39. Lee JH, Wei ZZ, Cao W, Won S, Gu X, Winter $M$, et al. Regulation of therapeutic hypothermia on inflammatory cytokines, microglia polarization, migration and functional recovery after ischemic stroke in mice. Neurobiol Dis. 2016; 96: 248-60.

40. Gu X, Wei ZZ, Espinera A, Lee JH, Ji X, Wei L, et al. Pharmacologically induced hypothermia attenuates traumatic brain injury in neonatal rats. Exp Neurol. 2015; 267: 135-42.

41. Faridar A, Bershad EM, Emiru T, Iaizzo PA, Suarez JI, Divani AA. Therapeutic hypothermia in stroke and traumatic brain injury. Front Neurol. 2011; 2: 80. doi: 10.3389/fneur.2011.00080.

42. Kollmar R, Blank T, Han JL, Georgiadis D, Schwab S. Different degrees of hypothermia after experimental stroke: short- and long-term outcome. Stroke. 2007; 38(5): 1585-9.

43. Tahir RA, Pabaney AH. Therapeutic hypothermia and ischemic stroke: a literature review. Surg Neurol Int. 2016; 7(14): S381-6.

44. Oddo M, Crippa IA, Mehta S, Menon D, Payen $\mathrm{J}-\mathrm{F}$, Taccone FS, et al. Optimizing sedation in patients with acute brain injury. Crit Care. 2016; 20(1): 128. doi: 10.1186/s13054-016-1294-5.

45. Maier CM, Sun GH, Kunis D, Yenari MA, Steinberg GK. Delayed induction and long-term effects of mild hypothermia in a focal model of transient cerebral ischemia: neurological outcome and infarct size. J Neurosurg. 2001; 94(1): 90-6.

46. Krieger DW, Yenari MA. Therapeutic hypothermia for acute ischemic stroke: what do laboratory studies teach us? Stroke. 2004; 35(6): 1482-9.

47. Marion D, Bullock MR. Current and future role of therapeutic hypothermia. J Neurotrauma. 2009; 26(3): 455-67.

48. GonzÃ ¡lez-Ibarra FP, Varon J, LÃ $\tilde{p}^{3}$ ez-Meza EG. Therapeutic hypothermia: critical review of the molecular mechanisms of action. Front Neurol. 2011; 2: 4. doi: 10.3389/fneur.2011.00004.

49. Pulsinelli W. Pathophysiology of acute ischaemic stroke. Lancet. 1992; 339(8792): 533-6.

50. Bach A. Targeting oxidative stress in stroke. Neuroprotective Therapy for Stroke and Ischemic Disease. 2017; p. 203-50.

51. Colbourne F, Grooms SY, Zukin RS, Buchan AM, Bennett MVL. Hypothermia rescues hippocampal CA1 neurons and attenuates down-regulation of the AMPA receptor GluR2 subunit after forebrain ischemia. Proc Natl Acad Sci U S A. 2003; 100(5): 2906-10.

52. Kim JY, Kim N, Yenari MA, Chang W. Mild Hypothermia Suppresses Calcium-Sensing Receptor (CaSR) Induction Following Forebrain Ischemia While Increasing GABA-B Receptor 1 (GABA-B-R1) Expression. Transl Stroke Res. 2011; 2(2): 195-201.

53. Kim JY, Ho H, Kim N, Liu J, Tu CL, Yenari MA, et al. Calcium-sensing receptor (CaSR) as a novel target for ischemic neuroprotection. Ann Clin Transl Neurol. 2014; 1(11): 851-66.

54. Alavian F, Hajizadeh S, Bigdeli MR, Javan M. The role of protein kinase $\mathrm{C}$ in ischemic tolerance induced by hyperoxia in rats with stroke. EXCLI J. 2012; 11: 188-97.

55. Alavian F, Hajizadeh S, Bigdeli MR, Javan M. Effect of intermittent normobaric hyperoxia and protein kinase $\mathrm{C}$ activity on blood-brain barrier permeability. Journal of Shahrekord University of Medical Sciences. 2012; 14(3): 40-50.

56. Dai DW, Wang DS, Li KS, Mao Y, Zhang LM, Duan $\mathrm{SR}$, et al. Effect of local mild hypothermia on expression of aquaporin-4 following intracerebral hemorrhage in rats. Europe PMC plus. 2006; 86(13): 906-10.

57. Tokutomi T, Morimoto K, Miyagi T, Yamaguchi S, Ishikawa K, Shigemori M. Optimal temperature for the management of severe traumatic brain injury: effect of hypothermia on intracranial pressure, systemic and intracranial hemodynamics, and metabolism. Neurosurgery. 2003; 52(1): 102-12.

58. Polderman KH, Peerdeman SM, Girbes ARJ. Hypophosphatemia and hypomagnesemia induced by cooling in patients with severe head injury. Journal of Neurosurgical Anesthesiology. 2001; 94(5): 697-705.

59. Feng J-f, Zhang K-m, Jiang J-y, Gao G-y, Fu Xa, Liang Y-m. Effect of therapeutic mild hypothermia on the genomics of the hippocampus after moderate traumatic brain injury in rats. Neurosurgery. 2010; 67(3): 730-42.

60. Kurisu K, Yenari MA. Therapeutic hypothermia for ischemic stroke; pathophysiology and future promise. Neuropharmacology. 2018; 134: 302-9.

61. Long S, Romani AMP. Role of cellular magnesium in human diseases. Austin J Nutr Food Sci. 2014; 2(10): 1051.

62. Btaiche I. Fluid, electrolytes, and nutrition in trauma 
patients. Encyclopedia of Trauma Care. 2015; 637-43.

63. Saito Y, Aoki Y, Takeshita E, Saito T, Sugai K, Komaki $\mathrm{H}$, et al. Hypophosphatemia is a common complication in severely disabled individuals with neurological disorders and is caused by infection, refeeding and fanconi syndrome. Brain and Development. 2014; 36(10): 878-83.

64. Buse S, Blancher M, Viglino D, Pasquier M, Maignan M, Bouzat $\mathrm{P}$, et al. The impact of hypothermia on serum potassium concentration: a systematic review. Resuscitation. 2017; 118: 35-42.

65. Han Z, Liu X, Luo Y, Ji X. Therapeutic hypothermia for stroke: where to go? Experimental Neurology. 2015; 272: 67-77.

66. Polderman KH, Herold I. Therapeutic hypothermia and controlled normothermia in the intensive care unit: practical considerations, side effects, and cooling methods. Crit Care Med. 2009; 37(3): 1101-20.

67. Gu LJ, Xiong XX, Ito T, Lee J, Xu BH, Krams S, et al. Moderate hypothermia inhibits brain inflammation and attenuates strokeâ€-induced immunodepression in rats. CNS Neurosci Ther. 2014; 20(1): 67-75.

68. Murray PJ, Wynn TA. Protective and pathogenic functions of macrophage subsets. Nat Rev Immunol. 2011; 11(11): 723-37

69. Huang Y-c, Feng Z-p. The good and bad of microglia/ macrophages: new hope in stroke therapeutics. Acta Pharmacol Sin. 2013; 34(1): 6-7.

70. Polderman KH. Induced hypothermia and fever control for prevention and treatment of neurological injuries. Lancet. 2008; 371(9628): 1955-69.

71. McKeownA M, Guerriero J, Letai A. Anti-tumor (M1) Macrophages Secrete Cytokines that Prime Breast Cancer Cells for Apoptosis. Undergraduate Research at the Swanson School of Engineering. 2017; 61-5.

72. Kim JY, Yenari MA. Hypothermia for treatment of stroke. Brain Circulation. 2015; 1(1): 14-25.

73. Fleming A, Vicinanza M, Renna M, Puri C, Ricketts $\mathrm{T}$, Füllgrabe J, et al. Neurodegenerative diseases and autophagy. The Molecular and Cellular Basis of Neurodegenerative Diseases. 2018; p. 299-343.

74. Fricker M, Tolkovsky AM, Borutaite V, Coleman M, Brown GC. Neuronal cell death. Physiol Rev. 2018; 98(2): 813-80.

75. Delorme-Axford E, Klionsky DJ. Secretory autophagy holds the key to lysozyme secretion during bacterial infection of the intestine. Autophagy. 2018; 14(3): $365-7$.

76. Halliwell B. Phagocyte-derived reactive species: salvation or suicide? Trends Biochem Sci. 2006; 31(9): 509-15.

77. Shaid S, Brandts C, Serve H, Dikic I. Ubiquitination and selective autophagy. Cell Death Differ. 2013; 20(1): 21-30.

78. Grumati P, Dikic I. Ubiquitin signaling and autophagy. J Biol Chem. 2018; 293(15): 5404-13.

79. Wei K, Wang P, Miao AD-E. A double-edged sword with therapeutic potential: an updated role of autophagy in ischemic cerebral injury. CNS Neurosci Ther. 2012; 18(11): 879-86.

80. Kaur J, Debnath J. Autophagy at the crossroads of catabolism and anabolism. Nat Rev Mol Cell Biol. 2015; 16(8): 461-72.

81. Tanida I, Ueno T, Kominami E. LC3 and Autophagy. Autophagosome and Phagosome. 2008; 445: 77-88.

82. Jing K, Lim K. Why is autophagy important in human diseases? Experimental \& molecular medicine (EMM). 2012; 44(2): 69-72.

83. Cheung SS, Lee JKW, Oksa J. Thermal stress, human performance, and physical employment standards. Applied Physiology, Nutrition, and Metabolism. 2016; 41(6): S148-S64.

84. Doufas AG, Lin C-M, Suleman M-I, Liem EB, Lenhardt R, Morioka N, et al. Dexmedetomidine and meperidine additively reduce the shivering threshold in humans. Stroke. 2003; 34(5): 1218-23.

85. Gozdemir M, Usta B, Demircioglu RI, Muslu B, Sert H, Karatas OF. Magnesium sulphate infusion prevents shivering during spinal anaesthesia: a randomised double blinded controlled study. J Clin Anesth. 2010; 22(3): 184-9.

86. Hemmen TM, Lyden PD. Hypothermia after acute ischemic stroke. J Neurotrauma. 2009; 26(3): 387-91.

87. Karnatovskaia LV, Wartenberg KE, Freeman WD. Therapeutic hypothermia for neuroprotection: history, mechanisms, risks, and clinical applications. Neurohospitalist. 2014; 4(3): 153-63.

88. Pokorna P, Wildschut ED, Vobruba V, van den Anker JN, Tibboel D. The impact of hypothermia on the pharmacokinetics of drugs used in neonates and young 


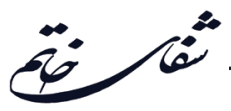

infants. Curr Pharm Des. 2015; 21(39): 5705-24.

89. Yenari MA, Palmer JT, Bracci PM, Steinberg GK. Thrombolysis with tissue plasminogen activator (tPA) is temperature dependent. Thromb Res. 1995; 77(5): 475-81.

90. Hemmen TM, Raman R, Guluma KZ, Meyer BC, Gomes JA, Cruz-Flores S, et al. Intravenous thrombolysis plus hypothermia for acute treatment of ischemic stroke (ICTuS-L). Stroke. 2010; 41(10): 2265-70.
91. Sumii T, Lo EH. Involvement of matrix metalloproteinase in thrombolysis-associated hemorrhagic transformation after embolic focal ischemia in rats. Stroke. 2002; 33(3): 831-6.

92. Takata K, Takeda Y, Sato T, Nakatsuka H, Yokoyama M, Morita K. Effects of hypothermia for a short period on histologic outcome and extracellular glutamate concentration during and after cardiac arrest in rats. Crit Care Med. 2005; 33(6): 1340-5. 